\title{
Potential of Terminalia arjuna as a Promising PhytoremedyAgainst COVID-19: DPPH Scavenging, Catalase Inhibition and Molecular Docking Studies
}

SenthilkumarArumugam ${ }^{\mathrm{a}}$, Swati S.Dash ${ }^{\mathrm{a}}$, Kartik Mitra ${ }^{\mathrm{b}}$, Mukesh Doble $^{\mathrm{b}}$ and Sathyanarayana N. Gummadi ${ }^{\mathrm{a}^{*}}$

${ }^{\mathrm{a}}$ Department of Biotechnology, Bhupat and Jyoti Mehta School of Biosciences, Applied and Industrial Microbiology Laboratory, Indian Institute of Technology Madras, Chennai, 600036 India

${ }^{b}$ Department of Biotechnology, Bhupat and Jyoti Mehta School of Biosciences, Drug Design Laboratory, Indian Institute of Technology Madras, Chennai, 600036 India

*Corresponding author

Phone: (+91)-44-2257-4114, Fax: (+91)-44-2257-4102, Email: gummadi@iitm.ac.in 


\section{ABSTRACT}

Stem and bark of the tree Terminalia arjuna Wight \&Arn. (Combretaceae) has been documented to exhibit therapeutic properties like cardiotonic, anticancer, antiviral, antibacterial, antifungal, hypocholsteremic, hypolipidemic and anti-coagulant. In previous studies, ethanolic extract of T.arjunabark effectively inhibited catalase activity along with demonstration of DPPH radical scavenging activity. Further,four known oleananetriterpenoids type compounds viz., oleanolic acid, arjunolic acid, arjunolitin, arjunetin were isolated from ethaolic bark extract and the structures of which were elucidated using ${ }^{1} \mathrm{H},{ }^{13} \mathrm{C}$ NMR, HR-ESIMS, IR and compared with literature data. Of the various compounds, Arjunetin showed significant inhibition of catalase activity as compared to the other compounds and most probably conferring antibacterial and antiviral property of the extract. In the present study, considering the currently on going viral pandemic of SARS-CoV-2 and the need for an effective antiviral agent, T.arjuna with its cardioprotective ability and inhibitory action against catalase presents to be a promising candidate against the virus. Molecular docking studies showed that arjunetin binds to protease of SARS-CoV-2 (3CL, PL andRdRP) and had higher binder energy values (3CL, -8.4 kcal/mol; PL, $-7.6 \mathrm{kcal} / \mathrm{mol}$ and RdRP, $-8.1 \mathrm{kcal} / \mathrm{mol}$ as compared with FDA approved protease inhibitor drugs lopinavir (3CL, -7.2 kcal/mole and PL -7.7 kcal/mole) and Remdesivir (RdRP -7.6 kcal/ mole). We conclude that there is profound evidence of arjunetin as a potential protease inhibitor of SARS-CoV-2 which is comparable to FDA approved antivirals Lopinavir and Remdesivir and can serve as a candidate for drug development against SARS-CoV-2.

KEY WORDS:Terminalia arjuna, DPPH scavenging, catalase inhibition, SARS-CoV-2, protease, arjunetin, molecular docking 


\section{Graphical abstract (TOC Graphics)}
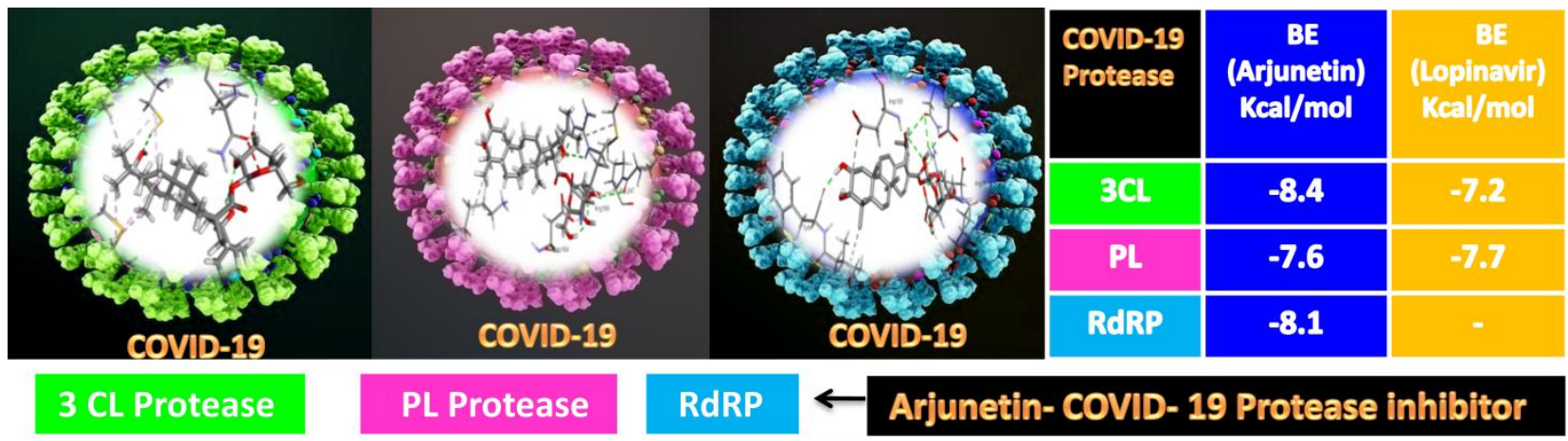

\begin{tabular}{|c|c|c|}
\hline $\begin{array}{c}\text { CoVID-19 } \\
\text { Protease }\end{array}$ & $\begin{array}{c}\text { BE } \\
\text { (Arjunetin) } \\
\text { Kcal/mol }\end{array}$ & $\begin{array}{c}\text { BE } \\
\text { (Remdesivir) } \\
\text { Kcal/mol }\end{array}$ \\
\hline RdRP & -8.1 & -7.6 \\
\hline
\end{tabular}

\section{Terminalia arjuna Bark Arjunetin-Catalase Inhibitor}

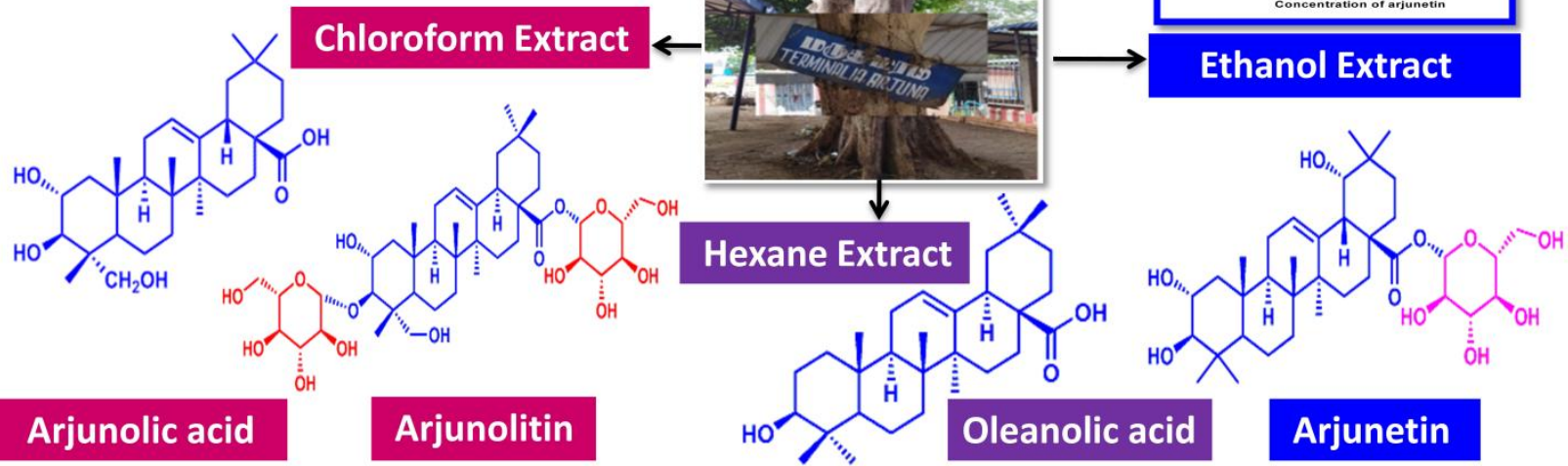




\section{INTRODUCTION}

The World Health Organization reported thatinfectious diseases caused by pathogenic microorganism account for about $25 \%$ of the total annual deaths that occur worldwide, both in developed as well as developing countries, the incidence being higher in developing nations ${ }^{1}$. In the present time, drastic changes in climate and increasing levels of pollutants in the atmosphere result in accelerating the rate of genetic mutations in these microorganismsthereby increasing their infectivity. Climate change also increases the contact of insect vectors and animal reservoirs of pathogens with humans, resulting in emergence of new diseases which are unresponsive to available treatment regimes. Overuse of antibiotics also leads to emergence of multi-drug resistant strains that are hard to eliminate. Therefore, discoveryof new and novel antibacterial and antivirals coupled with better understanding the mechanism of action is the present challenge in research.

In this aspect, plant derived phytochemicals can offer new direction in development of methods for disease control. Traditional systems of medicine such as Ayurveda, Siddha, or Unani have depended on natively available flora for treatment of almost all kinds of maladies since centuries. Terminaliaarjuna(TA) (Family: Combretaceae), a tree native to Indian subcontinent, is extensively used in many of traditional forms of medicine for the treatment of hypertension and coronary heart diseases ${ }^{2}$ earning it the epitaph of "Guardian of the heart". It is known to confer cardioprotective properties such as strengthening heart muscles and improving functioning of cardiac muscles, thereby alleviating heart failure, angina and hypercholesrolemia.Stem and bark of this plant exhibits various other therapeutic properties such asexpectorant, antidysentric,purgative, laxative and have been also used to treatleucoderma, anaemia, hyperhidrosis,asthama and tumors ${ }^{3}$. In addition, it has also been reported that the bark of T.arjunaalso possesses good anticancer, antiviral andantimicrobial activities $^{4-6}$.It has been 
hypothesized that the cardioprotective activity of TA bark extracts are likely by the activation of endogenous antioxidant molecules by triterpenesnamely arjunolic acid. ${ }^{7-9}$. However, knowledge on the mode of action of the component in the bark/stem that confers antimicrobial activity is lacking in literature.

Previous studies carried on elucidation of properties of T.arjuna showed that catalase activity was inhibited by ethanolic bark extract in vitro. ${ }^{10}$ The enzyme catalase is one of the endogenous antioxidant defense systems that helps in decreasing accumulation of reactive oxygen by decomposing hydrogen peroxide during cellular metabolism to water and molecular oxygen. It is postulated that catalase activity protects pathogens from inactivation by reactive oxygenspecies (ROS) in eukaryotic systems, making it a potential virulence factor in many bacterial pathogens.Studies have shown that catalase facilitates intracellular survival of bacterial pathogens such as Mycobacterium tuberculosis ${ }^{11}$,Campylobacter jejuni ${ }^{12}$,Helicobacter pylori ${ }^{13}$ andHerpes Simplex Virus ${ }^{14}$. It has been also reported that increased serum catalase activity may also alter immune function, viral replication, and/or repair processes ${ }^{15,16}$.In this regard, the catalase inhibitor in T. arjuna extract necessitates further research.

We believe T. arjuna stands as a strong contender for development of an effective therapeutic agentfor the current pandemic respiratory disease, COVID-19 which emerged in December 2019 and has been spreading at a rapid rate all over the world with high rate of infectivity and mortality. The viral pathogen, SARS-CoV-2, appears to spread more efficiently, making it difficult to contain and increasing its pandemic potential ${ }^{17,18}$. One of the important pathological aspect of COVID 19 is its effect on cardiovascular system and T. arjuna has well documented cardio protective properties, making it an excellent match. Catalase inhibition is another important aspect which has been shown to inhibit viral replication and spread.Literature shows 
that bark extract of T.arjuna possesses anti-herpesvirus activity in inhibiting viral attachment and penetration and also disturbing the late event of infection ${ }^{19}$.

Consolidating information available from literature and experiments conducted in our lab on T.arjuna extracts, it is evident that T.arjuna can be regarded as an apt candidate in the search of antivirals against COVID-19. In this study, different solvent extracts of TA and the purified compounds from ethanol extracts have been evaluated for their effect on catalase activity.Also, molecular docking studies of isolated compound from ethanolic bark extract with have been carried out on protease of SARS-CoV-2.With no antivirals or vaccines developed till datefor the epidemic, the present study will serve as a frontier for the muchneeded research on drug development for COVID-19.

\section{RESULTS AND DISCUSSION}

\subsection{2, 2-Diphenyl-1-Picrylhydrazyl (DPPH) Free Radical Scavenging Assay}

DPPHis stable free radical used widely to study scavenging activities of antioxidants that can donate a hydrogen atom. The unpaired electron in DPPH becomes paired in the presence of a free radical scavenger (antioxidant) and the extent of decrease in DPPH absorption is proportional to the concentration of radicals scavenged, according to principle of Blois. This change in absorbance produced by this reaction forms the basis of tests to determine ability of compounds to act as free radical scavengers. In this study, the free radical scavenging property of T. arjuna bark, extracted in various solvents, was analyzed by UV-Visible spectroscopy and EPR spectroscopy as described below:

\subsubsection{DPPH Assay with UV-Visible Spectrophotometer}

Scavenging of DPPH radicals, which have maximum absorption at $519 \mathrm{~nm}$ in ethanol by antioxidants, results in a decrease in absorption over time which can be monitored using a UV- 
visible spectrophotometer at room temperature. Scavenging capacity can be represented as \% inhibition of DPPH radical. In this study, marked decline of the absorption intensity at $517 \mathrm{~nm}$ was observed after adding $10 \mu \mathrm{l}$ of T.arjuna bark extracted in various solvents (hexane, chloroform, ethyl acetate, acetone, ethanol and water) individually to DPPH solution. The results from different bark extracts were compared with that from ascorbic acid, a known antioxidant, at various time intervals (Figure 1a-f).The decrease in absorption could be attributed to the phytochemicals in the bark extracts which donates protons to DPPH and decolorize it.
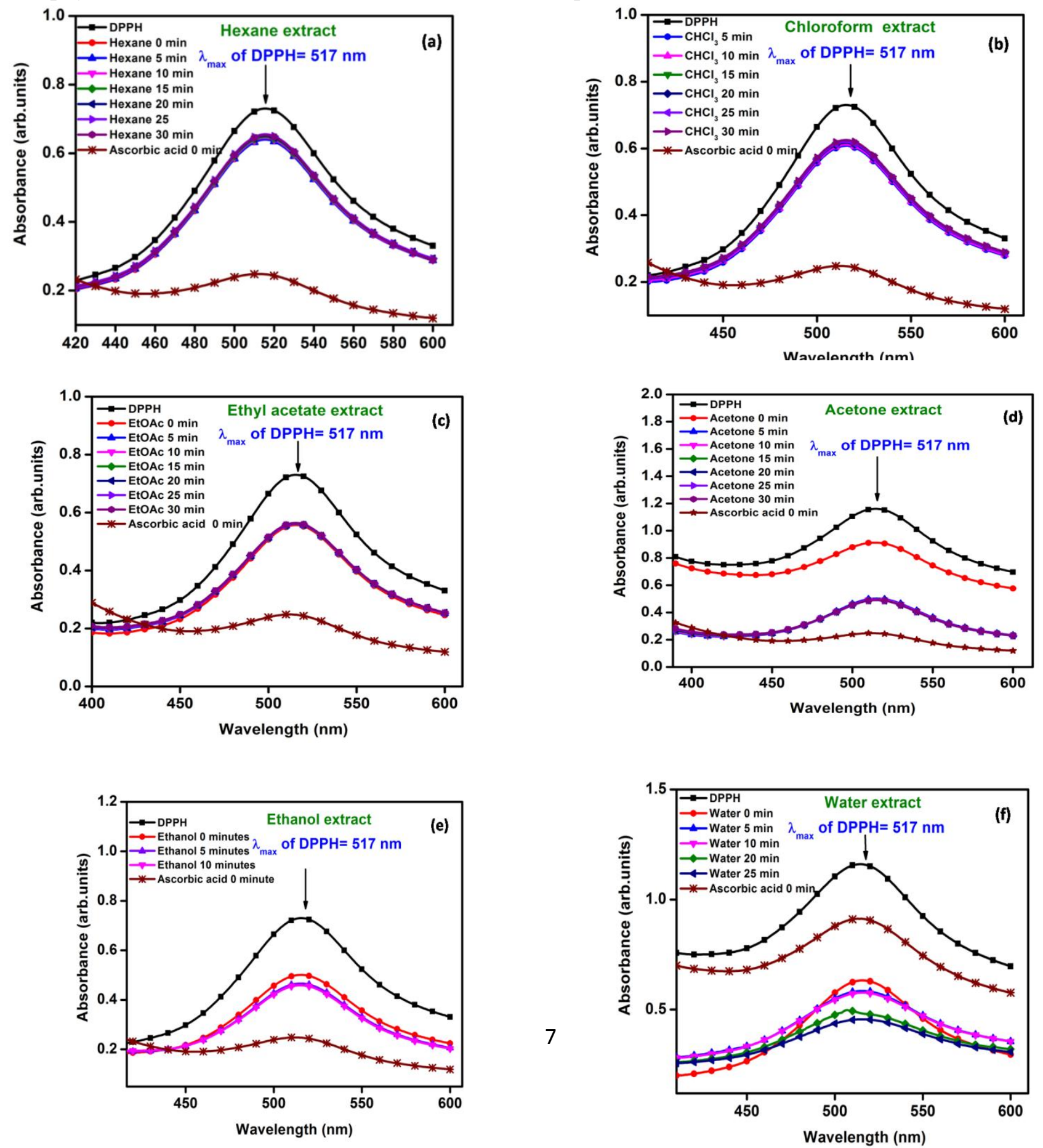
Figure 1. DPPH radical scavenging activity with different extracts by UV/vis (a) Hexane (b) Chloroform (c) Ethyl acetate (d) Acetone (e) Ethanol (f) Water.

It was found that the extracts varied significantly in terms of antioxidant activity. Ethanolic extract showed highest activity compared with other extracts which was equivalent to ascorbic acid, the standard antioxidant (Figure 2a and b) and Table 1. Percentage inhibition of DPPH radical scavenging activity at 5 minutes followed the order Ethanol $>$ Acetone $>$ ethyl acetate $>$ Water $>$ Chloroform $>$ Hexane (Table 1).
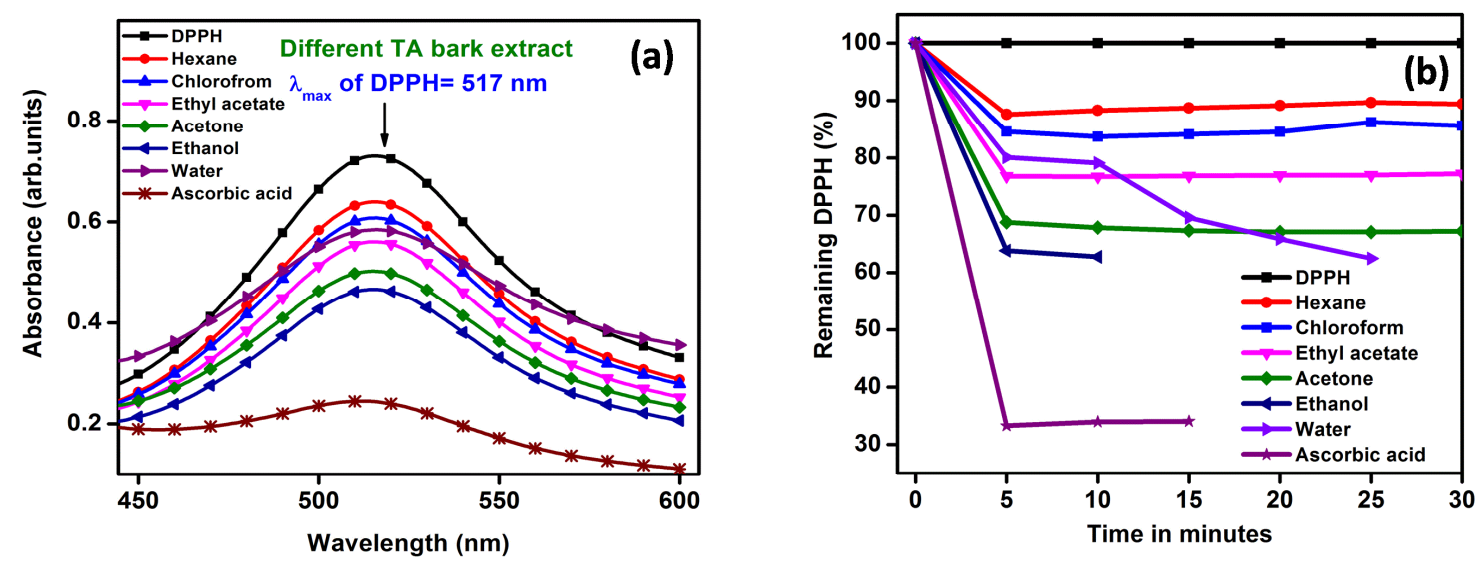

Figure 2. (a)Comparison of DPPH radical scavenging activity with different TA bark extract withDPPH and with standard (ascorbic acid) by UV/visible (b) Comparison \% Inhibitionfor different TA bark extract with DPPH and with standard (ascorbic acid) by UV/vis spectrum 
Table 1. \% of inhibitionof DPPH radical scavenging activity with different TA bark extract with DPPH and with standard (ascorbic acid).

\begin{tabular}{|c|c|c|c|c|c|c|c|}
\hline \multirow[t]{2}{*}{ SI.No. } & \multicolumn{2}{|c|}{ DPPH Scavenging activity } & \multicolumn{5}{|c|}{$\%$ of inhibition $(20 \mu \mathrm{l}$ of each extract $(1 \mathrm{mg} / \mathrm{mL})$} \\
\hline & Extracts & $5 \mathrm{~min}$ & $10 \mathrm{~min}$ & $15 \mathrm{~min}$ & $20 \mathrm{~min}$ & $25 \mathrm{~min}$ & $30 \mathrm{~min}$ \\
\hline 1 & Hexane & 12.41 & 11.69 & 11.27 & 10.86 & 10.31 & 10.56 \\
\hline 2 & Chloroform & 16.79 & 16.29 & 15.39 & 15.48 & 15.13 & 14.40 \\
\hline 3 & Ethyl acetate & 23.75 & 23.22 & 23.30 & 23.18 & 23.08 & 23.04 \\
\hline 4 & Acetone & 31.24 & 32.16 & 32.67 & 32.92 & 32.93 & 32.78 \\
\hline 5 & Ethanol & 36.18 & 37.25 & - & - & - & - \\
\hline 6 & Water & 19.93 & 20.91 & 34.13 & 37.28 & & \\
\hline 7 & Ascorbic acid & 66.72 & 66.11 & - & - & - & - \\
\hline
\end{tabular}

\subsubsection{DPPH Assay with EPR Spectroscopy}

EPR spectroscopy was used to quantify rate of DPPH radical disappearance in the presence of bark extract in this study. This technique has been used previously to assess free radicals scavenging ability of compounds ${ }^{20,21}$.EPR determination of antioxidant activity is based on measuring the changes in the intensity of the EPR spectrum of stable radicals that result from their interaction with bark extracts antioxidants.

In this study, the EPR spectrum of ethanolic solutions of DPPH with various extracts was compared to the spectrum obtained from pure DPPH in order to study the decline in DPPH signal intensity, which indicated scavenging. Ethanolic solutions of DPPH were mixed with solutions of prepared bark extract and decline in DPPH signal intensity was monitored by EPR (Figure 3).Antioxidant activity (AA) of different extracts was measured based on remaining DPPH residue $(\%)$ and it was in the order of Hexane $(77.10 \%)>$ Chloroform $(76.25 \%)>$ Ethyl acetate 
$(74.95 \%)>$ Acetone $(70.69 \%)>$ Ethanol $(68.10 \%)>$ Water $(65.23 \%)$ at 5 minutes. Based on above results antioxidant activity trends was observed in the order of Water $>$ Ethanol $>$ Acetone $>$ Ethyl acetate $>$ Chloroform $>$ Hexane, the decrease in DPPH peak intensity observed to be highest in water and ethanol extract(Figure 4 and Table 2 ) indicating their superior antioxidant property as compared to extracts in other solvents. This is in correlation with previous studies ${ }^{22,23}$.
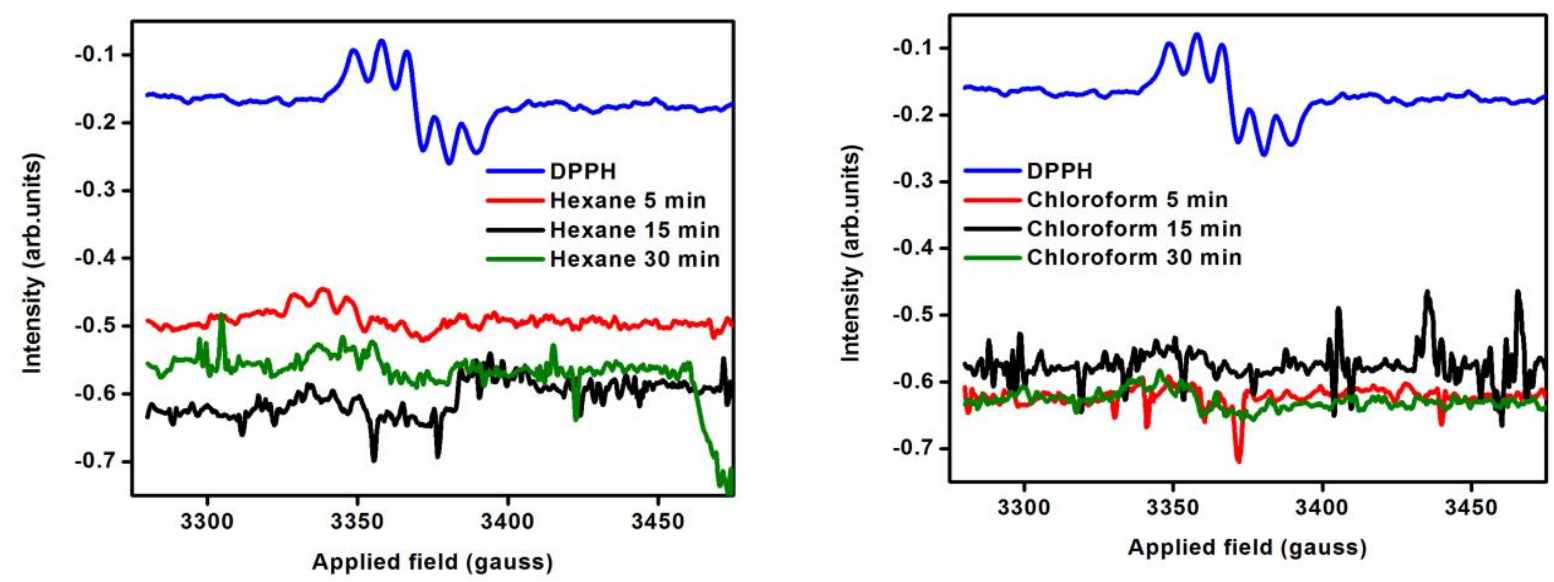

(b)

(c)
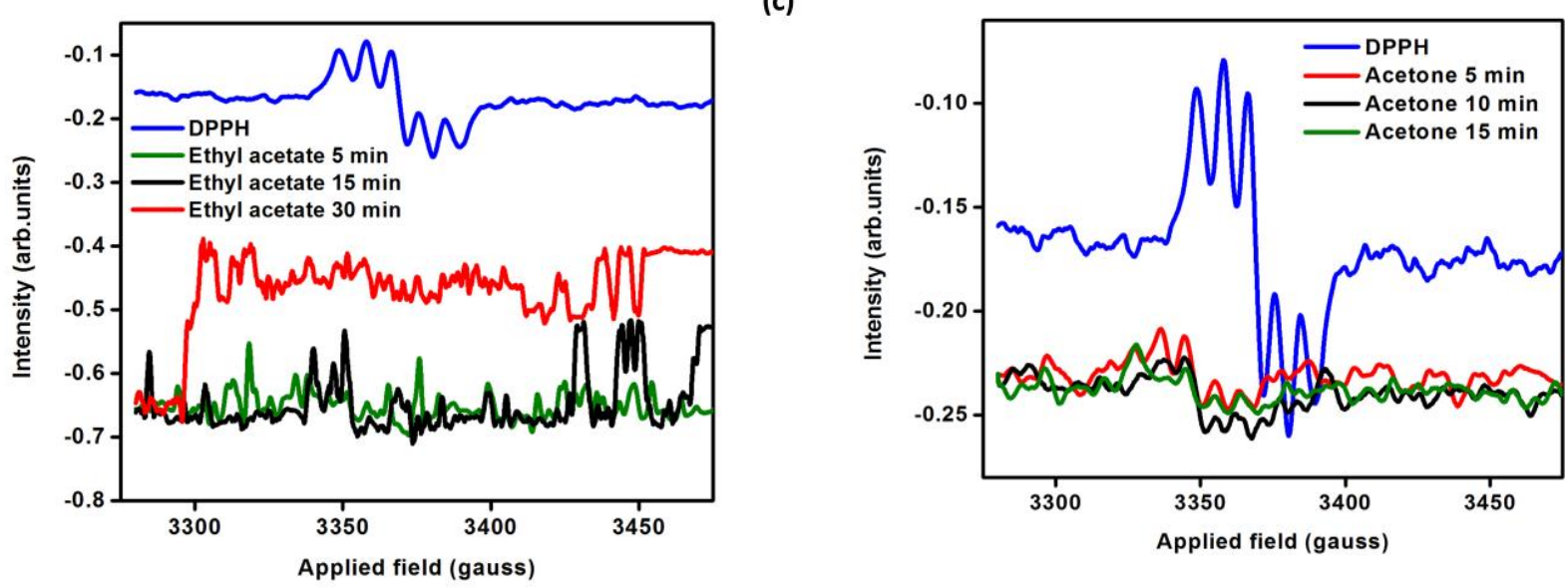

(d)

(e)
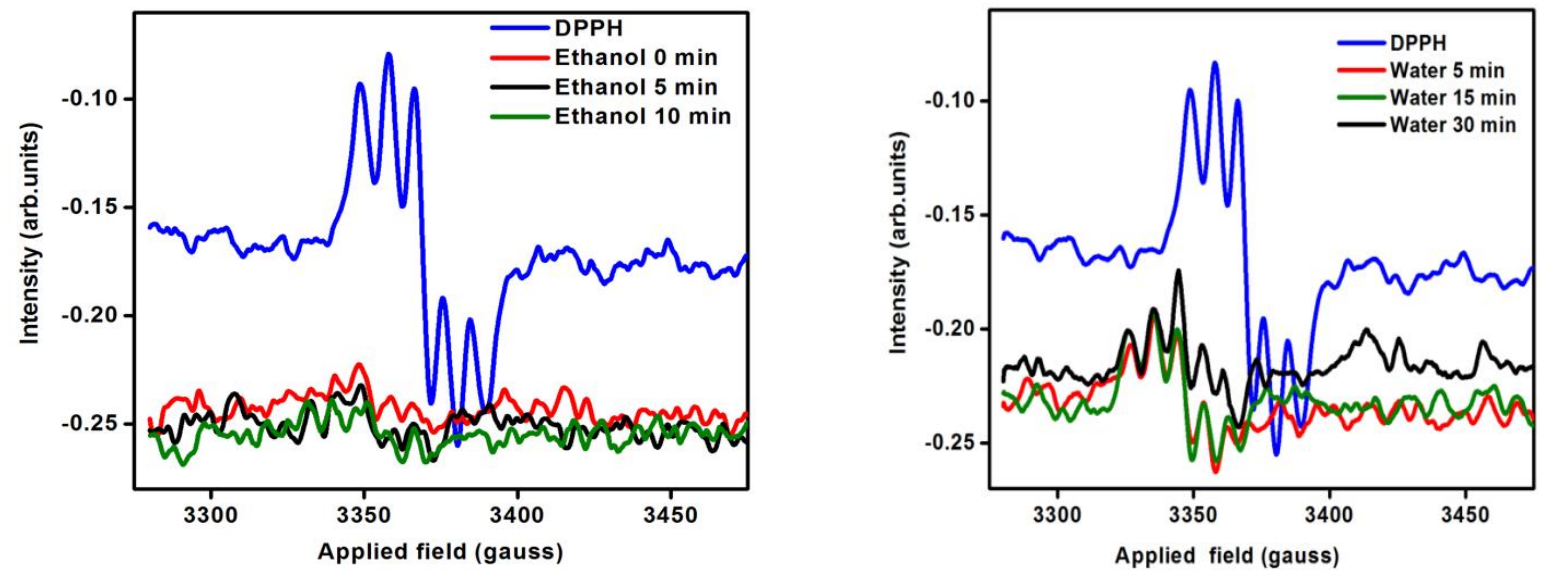

(f) 
Figure 3.EPR spectra of DPPH with various extract (a) Hexane extract (b) Chloroform extract (c) Ethyl acetate extract (d) Acetone extract (e) Ethanol extract (f) Water extract.

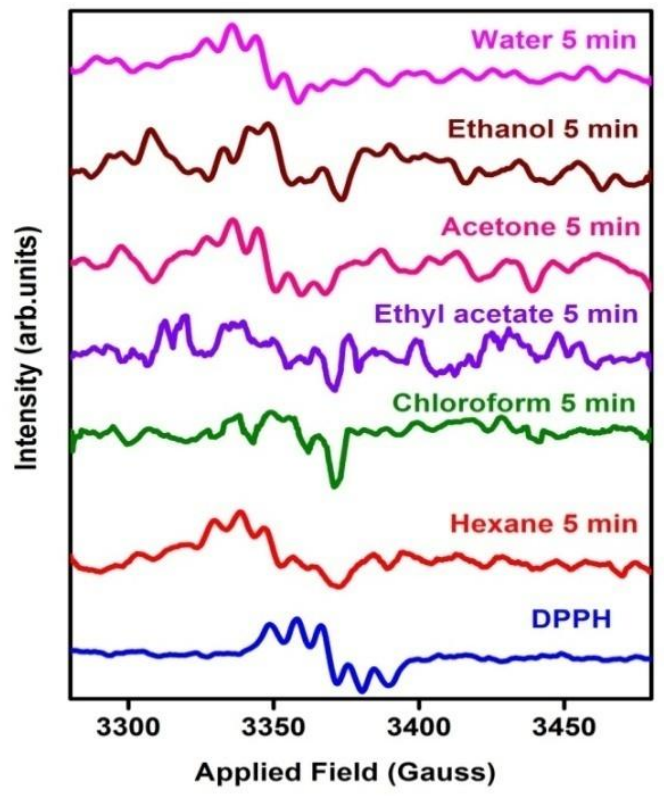

Figure4.Comparison of the EPR spectra of DPPH and different TA extract with DPPH at 5 min.

Table 2.Calculation antioxidant activity (AA) of different TA extracts using EPR

\begin{tabular}{|c|c|c|c|c|}
\hline \multicolumn{5}{|c|}{$\begin{array}{c}\text { Antioxidant activity (AA) of different extracts } \\
\text { Remaining DPPH Residue (\%) }\end{array}$} \\
\hline \multicolumn{5}{|c|}{ Time } \\
\hline Extracts & 0 min & $\mathbf{5}$ min & 10 min & 15 min \\
\hline Hexane & 77.30 & 77.10 & 76.35 & 75.01 \\
\hline Chloroform & 76.53 & 76.25 & 76.05 & 75.65 \\
\hline Ethyl acetate & 75.36 & 74.95 & 73.20 & 72.85 \\
\hline Acetone & 73.65 & 70.69 & 62.50 & 61.35 \\
\hline Ethanol & 71.59 & 68.10 & 66.62 & - \\
\hline Water & 66.66 & 65.23 & 64.76 & 63.41 \\
\hline
\end{tabular}




\subsection{Mechanism of DPPH with TA Extract}

Polyphenolic compounds in TA extract are good reducing agents because of the hydrogen donor properties of their phenolic hydroxyl groups. When DPPH solution is mixed with TA extract, the phenolic compounds donate hydrogen atoms, thereby converting DPPH to its reduced form with a resulting decrease in absorbance at $517 \mathrm{~nm}$.

Earlier studies on ethanolextraction, this type of triterpenoids glycoside compound revealed that certain structural features improve the efficiency in the trapping of DPPH radicals, such as hydroxyl groups and a ester glycoside, which increase the electronic delocalization in the molecule and it contributes to the stability of the produced radicals, resulting in an increase in the DPPH radical-scavenging capacity ${ }^{24}$ (Sanchez et al 2010)

The DPPH assay is based on both single electron transfer (SET) and hydrogen atom transfer (HAT) reactions. Antioxidants react with free radicals by different mechanisms hydrogen atom transfer (HAT) or single electron transfer mechanism (SET); or the combination of both HAT and SET mechanisms. Details of the mechanism have been given in the supplementary section (Figure S1). Ethanol extract from T.arjunahas the proton-donating capacity and could serve as inhibitor of free radical and probably as a primary antioxidant ${ }^{25,26}$.Considering the obtained results, TA ethanol extract showed a potent antioxidant activity as indicated by the scavenging ability observed against DPPH radicals.

\subsection{Isolation and Structure Elucidation}

4 different compounds were isolated from TA extracts and were identified using IR spectrum studies, ${ }^{13} \mathrm{C}$ NMR and ${ }^{1} \mathrm{HNMR}$. Compounds 1,2 and 3 were identified asoleanolic acid, arjunolicacid and arjunolitin. Details of all spectrophotometric data have been provided in the supplement section (Figures S2-S4). 
Compound 4 was obtained as colorless solid from ethanol fraction using 100\% methanol as eluent. It showed UV $\lambda_{\max }$ (methanol) $423 \mathrm{~nm}$. It exhibited characteristic IR absorption bands trisubstituted double bonds $\left(1630 \mathrm{~cm}^{-1}, 894 \mathrm{~cm}^{-1}\right)$, hydroxyl $\left(3355 \mathrm{~cm}^{-1}\right)$, ester $\left(1730 \mathrm{~cm}^{-1}\right)$, methyl $\left(1452 \mathrm{~cm}^{-1}\right)$, gem dimethyl $1391 \mathrm{~cm}^{-1}$, C-O stretching frequency $\left(1260,1161,1049 \mathrm{~cm}^{-}\right.$ ${ }^{1}$ ). On the basis of mass and ${ }^{13} \mathrm{C}$ NMR spectra the molecular ion peak of 4 was determined at $m / z 673.4[\mathrm{M}+\mathrm{Na}]^{+} \mathrm{C}_{36} \mathrm{H}_{58} \mathrm{NaO}_{10}, m / z 689[\mathrm{M}+\mathrm{K}]^{+}, m / z 511[\mathrm{M}-162]^{+}, m / z 527[\mathrm{M}-162-44]^{+}$, $m / z 430[\mathrm{M}-162-44-34]^{+}, m / z 413[\mathrm{M}-162-44-41]^{+}$supported one glycoside, three removable hydroxyl group and one ester function in the molecule.

${ }^{1} \mathrm{H}$ NMR spectrum of compound (4) exhibited signals of an olefinic proton at $\delta_{\mathrm{H}} 7.0(1 \mathrm{H}, \mathrm{brs}, \mathrm{H}-$ 12) and seven methyl singlet's $\delta_{\mathrm{H}}\left(0.12,0.16,0.19,0.33,0.36,0.40,0.57,7 \mathrm{XCH}_{3}, 21 \mathrm{H}\right)$, the spectrum showed three oxygen bearing methine protons at $\delta_{\mathrm{H}} 4.47(1 \mathrm{H}, \mathrm{brs}, \mathrm{H}-19), \delta_{\mathrm{H}} 4.66(1 \mathrm{H}$, s, H-3 $), \delta_{\mathrm{H}} 4.73(1 \mathrm{H}, \mathrm{d}, J=9.5 \mathrm{~Hz}, \mathrm{H}-2 \beta), \delta_{\mathrm{H}} 3.48\left(1 \mathrm{H}\right.$, brs-H18), $\delta_{\mathrm{H}} 3.32-3.89$ (glucose hydrogen's). ${ }^{13} \mathrm{C}$ NMR spectrum displayed 36 signals inclusive of seven methyl signals $\delta_{\mathrm{C}}(13.9$, $16.9,17.0,17.6,23.5,25.8$, and 27.3), three secondary hydroxyl groups $\delta_{\mathrm{C}} 69.7(\mathrm{C}-2), 75.6(\mathrm{C}-$ 3), 77.9 (C-19), one trisubstituted double bond $\delta_{\mathrm{C}} 121.8$ (C-12),144.2 (C-13), ester carbonyl $\delta_{\mathrm{C}}$ 175.4 (C-28), glucose carbon $\delta_{\mathrm{C}} 60.2,60.8,67.6,72.5,76.8,94.26$. The anomeric proton signals at $\delta_{\mathrm{H}} 6.8\left(1 \mathrm{H},-\mathrm{H} 1{ }^{\prime}\right)$ in the ${ }^{1} \mathrm{H}$ NMR spectrum and anomeric carbon signals at $\delta_{\mathrm{H}} 94.2$ in the ${ }^{13} \mathrm{C}$ NMR spectra of compound attributed to a $\beta$-glucose unit linked to the $\mathrm{C}_{28}$ carbonyl group of the genin through an ester bond ${ }^{4,27,28}$. From the above all spectroscopic data the compound 4 was named as arjunetin.

Previous results showed that ethanolic extract had significantly higher antioxidant ability compared to extracts from other solvents. Since arjunetin is the identified phytochemical in the ethanol fraction it may have higher therapeutic significance as compared to other compounds 
isolated and identified. This is further confirmed in our studies on catalase inhibition as described in the next section.

\subsection{Catalase Assay with Arjunetin (Compound4) from Ethanol Extract of TA Bark}

Different bark extracts of T.arjuna showed inhibition of catalase activity. Amongst the all the extracts least inhibition was noted with chloroform extract and maximum inhibition was observed with ethanol extract(Figure 5). Dose dependent studies of isolated arjunetin molecule from ethanolic bark extract on catalase activity showed that inhibitory effect increased with increasing concentration of arjunetin (Figure 6).This is in contrast with previous findings where it has been observed that ethanolic bark extracts enhanced the catalase levels in vivo in ischemic
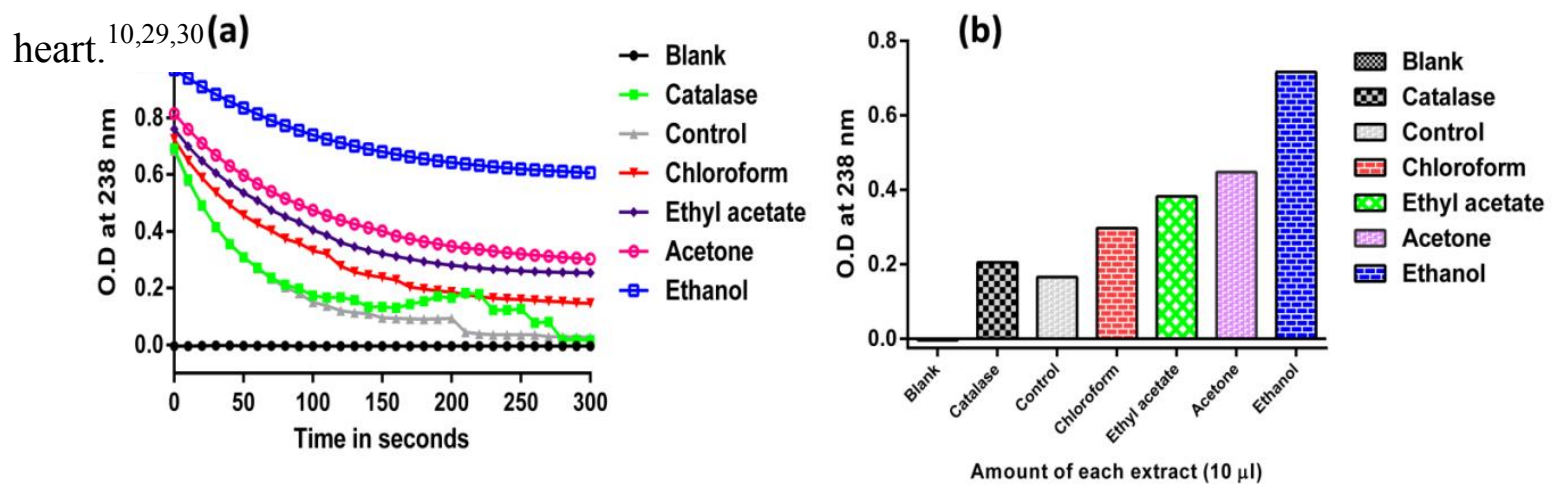

Figure 5:Effect of T. arjunabark extracts on catalase activity. (a) Comparison of catalase activity with different $T$. arjunabark extract. (b) Bar graph of comparison of catalase activity with different $T$. arjunabark extract.

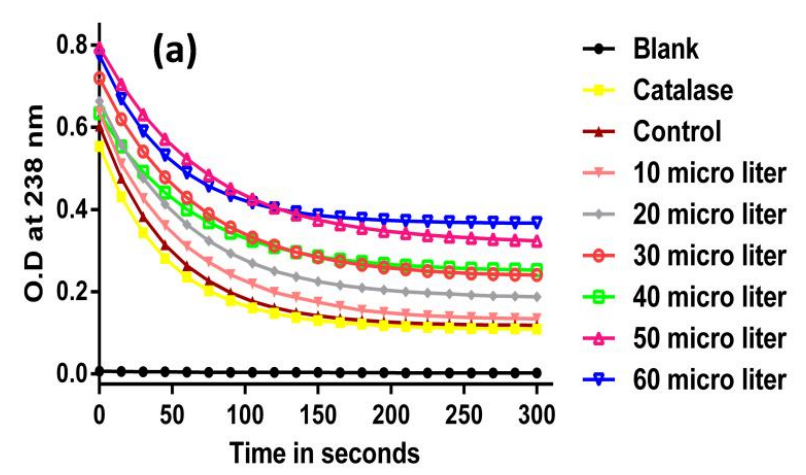

(b)

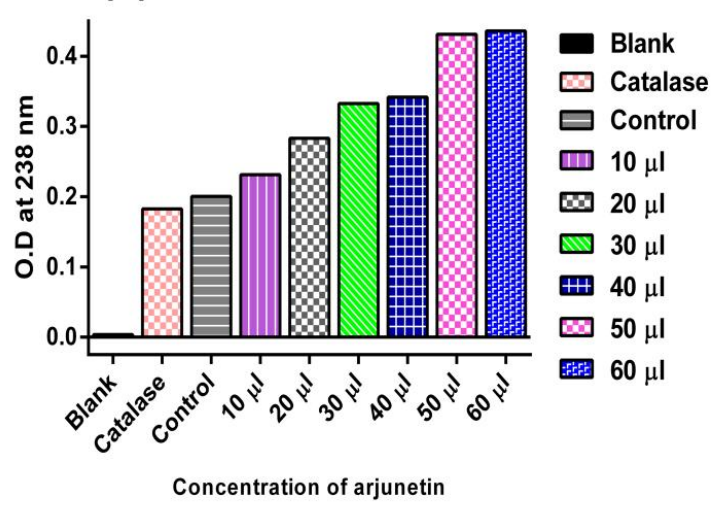


Figure 6:Effect of arjunetin from ethanol extract of $T$. arjunabark on catalase activity (a) Comparison of catalase activity with different amounts of arjunetin. (b) Bar graph of comparison of catalase activity with different amounts of arjunetin

The binding efficiency is attributed to the hydroxyl groups and ester glycoside present in arjunetin, which serve as hydrogen bond donors. Involvement of positive charge on the carbon atom of the ester bond with the electronegative groups of amino acid residues like histidine also contributes towards efficient binding. Here it can be reasoned that at this concentration of arjunetin it can also bind to other non-specific targets in vivo due to the presence of $\mathrm{OH}$ groups.

Catalase is an antioxidant oligomeric enzyme ( $\mathrm{MW}=2,40,000)$ with four identical subunits arranged tetrahedrally. In eukaryotes it plays an important role in protecting cells from oxidative damage due to ROS. However, in certain bacteria and viruses, catalase is present as avirulant factor and is very important for the intracellular survival of the pathogen and disease progression. In this regard, compoundsthat bind to catalase and elicit enzyme inhibition can act as efficient antimicrobial and antiviral agents.It is known that inhibitor 3-AT (an efficient inhibitor of catalase) binds with histidine residue (His75) near heme group of catalase forming a non-coplanar adduct (very close to Tyr358). Loss in activity of catalase suggests involvement of arjunetincation with histidine anion $(\mathrm{pKa}=6.5)$ near tyrosine residue (Tyr358) of active site. This information can be used in in-silico methods of drug development using arjunetin.

In the present study, physiological changes have been demonstrated by inhibition of catalase by arjunetin. From the decay curves as shown in Figure 6, it is inferred that the rate of $\mathrm{H}_{2} \mathrm{O}_{2}$ degradation is reduced by arjunetin, proving arjunetin to be a good catalase inhibitor and therefore has potential to be studied for the development of an effective antibiotic.

SARS-CoV-2, the virus behind COVID-19 has no cure till date. Two main pathophysiologies of this disease is its effect on cardiovascular system and the development of adult respiratory 
distress syndrome (ARDS). Studies have shown that serum catalase activity increases in septic patients with $\mathrm{ARDS}^{31}$. Considering the cardioprotective nature of T.arjuna and the ability to inhibit catalase, there is immense promise in this molecule for further research and use in development of an effective cure against SARS-CoV-2.

\subsection{Inhibition of SARS-CoV-2 Protease byArjunetin:Molecular Docking Studies}

Since the appearance of COVID-19 pandemic, researchers all over the world have been proactively searching for a cure. Remdesivir was used in the first case of COVID-19 during January 2020 in Washington.Remdesivir, the single Sp isomer of the 2-ethylbutyl Lalaninatephosphoramidate prodrug, has been reported to inhibit COVID-19 virus proliferation and therefore has clinical potential. FDA approved HIV protease inhibitors such as lopinavir and ritonavir have been reported to be active against SARS and MERS. Clinical trials have been initiated to test HIV protease inhibitors such as lopinavir and ritonavir in patients infected with novel coronavirus SARS-CoV-2.

In addition, natural compounds purified from plants can prove to be effective against the virus. Several plant-based treatment strategies against viral infections have been well elucidated in traditional medicine, many of which have the potential to be evaluated for COVID-19 $9^{32}$.

Since it may take a long time to come up with a concrete remedial measure, use of in-silico tools will be beneficial in short listing candidate molecules for further research. In-silico screening of natural compounds using molecular docking have already been carried out on numerous listed plant derived compounds with an aim to create a library for reference and research (Joshi et al., 2020). It was of our interest therefore to study inhibition of SARS-CoV-2 proteases by arjunetin, the bioactive component isolated from T.arjuna, via molecular docking. Lopinavir and ritonavir have been used as control for our study $y^{33,34}$. 
In this study, molecular docking of arjunetin was performed against SARS-CoV-2 3CL-protease, PL-protease and RNA-polymerase. Lopinavir was used as reference control for proteases. In case of 3CL-protease Arjunetin has better binding energy $(-8.4 \mathrm{Kcal} / \mathrm{mol})$ compared to lopinavir. $(-7.2 \mathrm{kcal} / \mathrm{mol})$ (Figure 7$)$. In case of arjunetin the interactions are predominantly hydrophobic contributed by LEU 141 and 27, whereas in case of lopinavir it was hydrophilic. In case of PLprotease, Arjunetin binding score $(-7.6 \mathrm{Kcal} / \mathrm{mol})$ is similar to Lopinavir $(-7.74 \mathrm{kcal} / \mathrm{mol})$ (Figure 8) the binding score of Arjunetin towards SARs-CoV-2 RdRP polymerase was found to be -7.8 $\mathrm{kcal} / \mathrm{mol}$. Similarly, the binding score of SARs-CoV-2 RdRP with Remdesivir was found to be $7.6 \mathrm{kcal} /$ mole (Figure 9), thereby indicating that arjunetin might preferably inhibit 3CL-protease as compared to PL-protease and RNA polymerase and better binding energy values as compared to Remdesivir, Lopinavir (Table $3 \& 4$ ). These results, combined with the previously elucidated antioxidant and catalase inhibitory properties of arjunetin make it a promising plant compound to be further evaluate against COVID-19. 


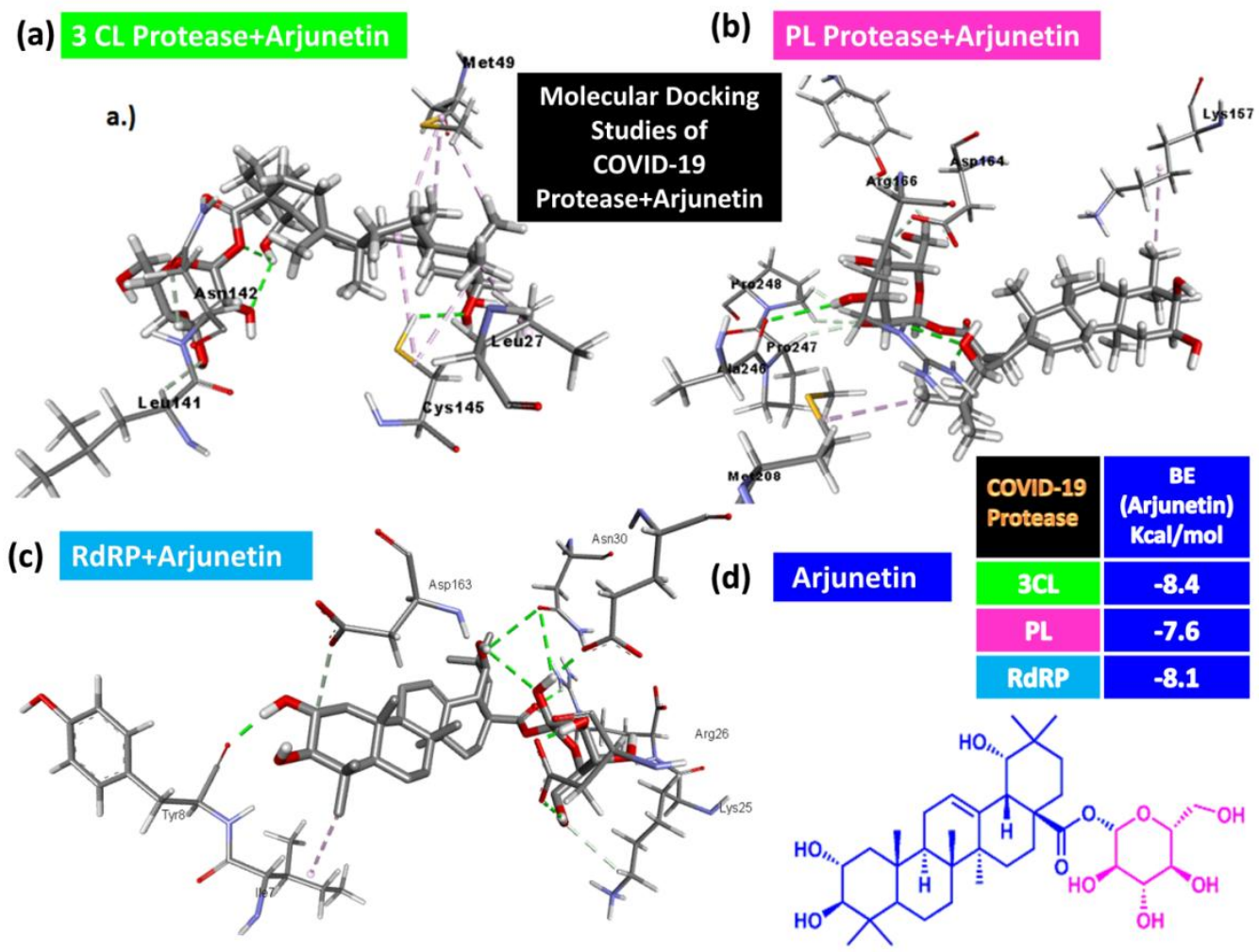

Figure 7:Molecular docking studies of SARS-CoV-2 protease with arjunetin(a) 3D interaction of 3CL+ arjunetin (b) 3D interaction of PL+ arjunetin, (c) 3D interaction of RdRP with arjunetin (d) Structure of arjunetin and binding energy values of SARS-CoV-2 protease with arjunetin. 


\section{Molecular Docking Studies of COVID-19 \\ Protease+Lopinavir}

(a) 3 CL Protease+Lopinavir

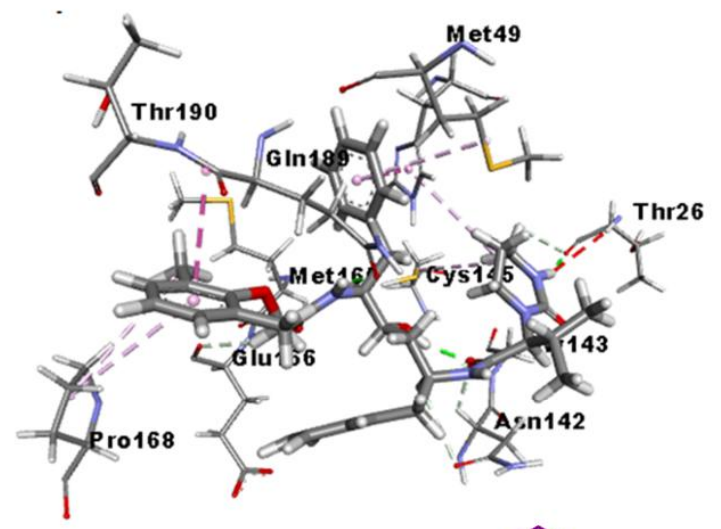

(c) Lopinavir

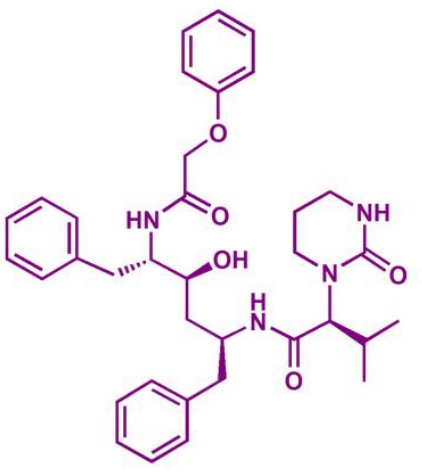

(b) PL Protease+Lopinavir

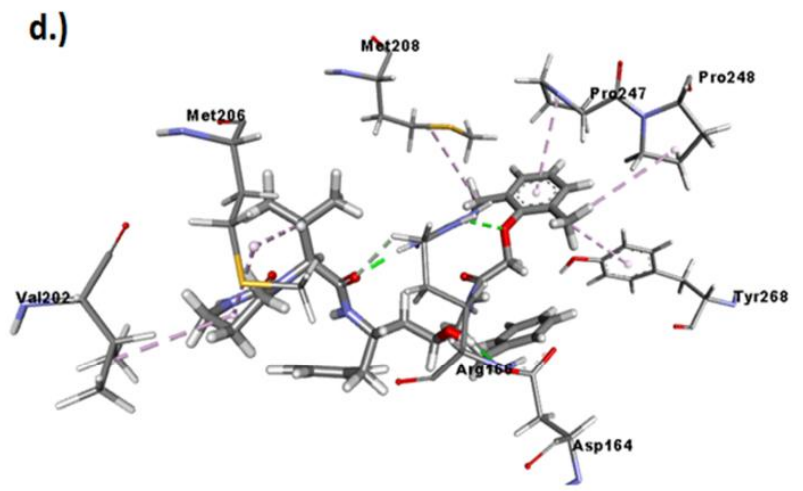

(d)

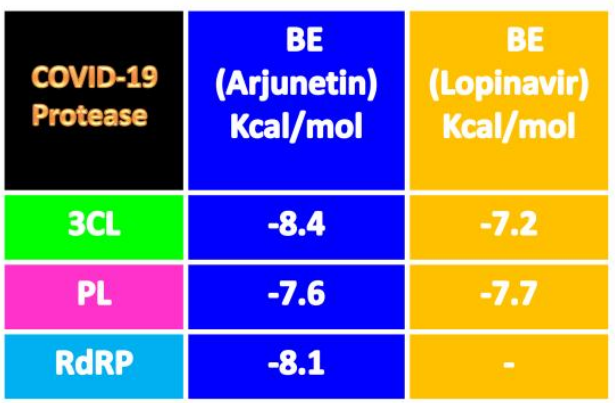

Figure 8:Molecular docking studies of SARS-CoV-2 protease with Lopinavir(a) 3D interaction of 3CL+Lopinavir, (b)3D interaction of PL+ Lopinavir,(c) Structure ofLopinavir (d ) Binding energy values of SARS-CoV-2 protease with Lopinavir 


\section{Molecular Docking Studies of COVID-19 Protease+ Remđesivirip}

(a) 3D-RdRP+Remdesivir

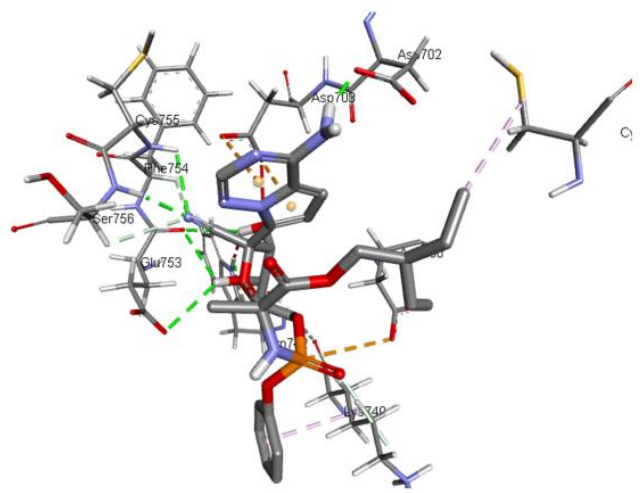

(c)

$$
\text { Remdesivir }
$$

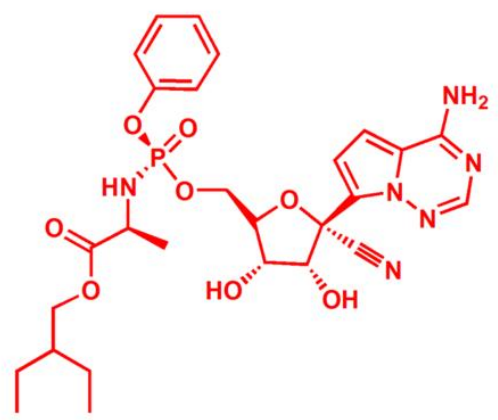

(b)

\section{D-RdRP+Remdesivir}

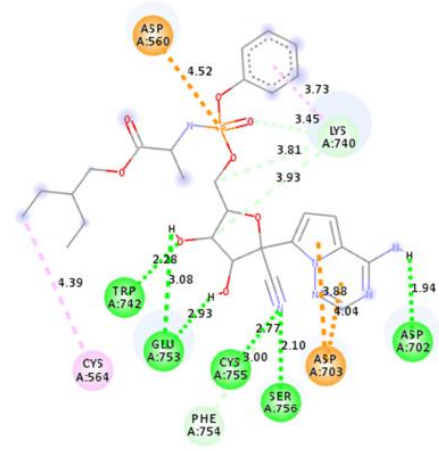

Interactions

Attractive Charge

Conventonal Hydrogen Bond

Pl-Arion
$\square$ Akyl
$\square$ Pi-Alkyl

(d)

\begin{tabular}{|c|c|c|}
\hline $\begin{array}{c}\text { CoviD-19 } \\
\text { Protease }\end{array}$ & $\begin{array}{c}\text { BE } \\
\text { (Arjunetin) } \\
\text { Kcal/mol }\end{array}$ & $\begin{array}{c}\text { BE } \\
\text { (Remdesivir) } \\
\text { Kcal/mol }\end{array}$ \\
\hline RdRP & -8.1 & -7.6 \\
\hline
\end{tabular}

Figure 9:Molecular docking studies of SARS-CoV-2 protease RdRP with remdesivir a) 3D interaction of RdRP with remdesivir b)2D interaction of RdRP with remdesivir v) Structure of remdesivir d) Binding energy values of SARS-CoV-2 proteaseRdRP with remdesivir

Table 3: Comparison of binding energy values of SARS-CoV-2 proteases 3CL, PL and RdRPwitharjunetin, lopinavir andremdesivir.

\begin{tabular}{|c|c|c|c|}
\hline \multirow{2}{*}{$\begin{array}{c}\text { COVID-19 } \\
\text { Protease }\end{array}$} & \multicolumn{3}{|c|}{ Binding Energy (K cal/mol } \\
\cline { 2 - 4 } & Arjunetin & Lopinavir & Remdesivir \\
\hline 3 CL & -8.4 & -7.2 & - \\
\hline PL & -7.6 & -7.7 & - \\
\hline RdRP & -8.1 & - & -7.6 \\
\hline
\end{tabular}


Table 4:Key interaction of antivirals with amino acids in SARS-CoV-19 proteases; 3CL, PL and RdRP with arjunetin, 3CL and PL with Lopinavir andRdRP with Remdesivir.

\begin{tabular}{|c|c|c|c|}
\hline Molecules & 3CL-protease & PL -protease & RdRP \\
\hline Arjunetin & $\begin{array}{c}\text { Leu141, Leu27, Cys145, } \\
\text { ASN12 and Met49 }\end{array}$ & $\begin{array}{c}\text { Pro248, Met208, Pro247, and } \\
\text { Lys157 }\end{array}$ & $\begin{array}{c}\text { ARG26, Lys25, Asp160, } \\
\text { Glu34, ASN30, Asp163, } \\
\text { Tyr8, ILE 7 }\end{array}$ \\
\hline Lopinavir & $\begin{array}{c}\text { Met 49, Pro168, ASN142, } \\
\text { Cys145, Th190 and Thr 26 }\end{array}$ & $\begin{array}{c}\text { ASP164, Pro248, Met206, } \\
\text { Val202, Tyr 260 }\end{array}$ & - \\
\hline \multirow{2}{*}{ Remdesivir } & - & - & $\begin{array}{c}\text { Asp560, Lys 740, } \\
\text { Cys564, } \\
\end{array}$ \\
& & & $\begin{array}{c}\text { Trp742, Glu753, Cys755, } \\
\text { Phe754, Ser756, Asp 703 }\end{array}$ \\
\hline
\end{tabular}

\section{CONCLUSIONS}

The present study was carried out to identify and evaluate active components in solvent extracts of T.arjuna bark samples, which is known for its cardioprotective and antimicrobial properties. Ethanolic extracts had significantly higher free radical scavenging ability as compared to other extracts, indicating their antioxidant nature. Further the purified compounds arjunetinfrom ethanolic bark extract showed dose dependent inhibition of catalase activity in-vitro. Molecular docking studies on arjunetin against three proteases of SARS-CoV-2 viz. 3CL, PL and RdRPdemonstrated that arjunetin can bind more efficiently to the viral proteases as compared to known commercially available antivirals thereby acting as inhibitor. We conclude that T.arjuna and its phytochemicals, particularly arjunetin, show promise as potential antiviral agents and can be utilized for further innovation and development of antiviral treatment regime against COVID19. 


\section{METHODS}

4.1. Collection of Plant Materials. The dry stem bark ofTerminaliaarjunawas obtained from Centre of Traditional Medicine and Research (CTMR), Chennai, India and collected from Pillaiyarpattai, Sri KarpagamVinayagerTemple thalaviruksha, Sivagangai District, Tamil Nadu, India and authenticated at Siddha Central Research Institute, Arumbakkam, Chennai,TamilNadu,India (voucher specimen no: T19081901A).

\subsection{Chemicals and Reagents}

Bovine serum catalase(CAS Number. 9001-05-2) and DPPH (2,2-Diphenyl-1-picryl hydrazyl radical) CAS Number 1898-66-4 was obtained from Sigma Aldrich, USA. Silica gel (230-400 mesh) and Sephadex LH-20 column obtained from Merck India and GE Healthcare, India respectfully. All the solvents used for extraction were AR grade procured in India. Ethanol (95\% $\mathrm{v} / \mathrm{v}$ technical grade) was purchased from Hayman, India.

4.3. Preparation of the Crude Extract. Air dried and finely powdered T.arjunabark (75g) was extracted using Soxhletapparatus with various solvents for $72 \mathrm{~h}$ using sequential refluxing with solvents of increasing polarity hexane $(100 \mathrm{mg})$, chloroform $(400 \mathrm{mg})$, ethyl acetate $(240 \mathrm{mg})$, acetone (3g), ethanol (12g) and water (3g).After filtration and evaporation of solvents under vacuum, the residueswere stored under room temperature.Phytochemical testswere carried out to detect presence of tannins, alkaloids, reducing sugars, saponins, flavanoid. Extracts of ethyl acetate, acetone, and ethanol had more tannins and extracts of hexane, ethyl alcohol and ethyl acetate were rich in flavonoid as reported in previous paper. ${ }^{10}$

4.4. Extraction and Isolation of Compounds fromT.arjunaBark. $1.5 \mathrm{~kg}$ of airdried bark of TA was ground to fine powder and sequentially extracted with solvents of increasing polarity 
(hexane, chloroform, and ethanol each solvent 5L) for $72 \mathrm{~h}$ using Soxhlet apparatus. After filtration, evaporation was done under vacuum and the residues were stored at room temperature. A glass column $(60 \mathrm{~cm}$ X $50 \mathrm{~mm})$ packed with silica gel $(60-120 \mathrm{mesh})$ was used as stationary phase for the separation of phytochemicals in solvent extracts. Hexane fraction $(10 \mathrm{~g})$ was eluted by column chromatography over silica gel(60-120 mesh) using varying concentration of chloroform in hexane as eluent $(0-100 \%$ chloroform) to afford two fractions one at hexanechloroform(9:1)to yield the mixture of compounds and at (1:1) to yield compound 1(50 $\mathrm{mg}$ ).Chloroform fraction (55g)was subjected to chromatography on silica geleluting with hexane-EtOAc-methanol gradient to afford five fractions A-E.Fraction C (4:1, ethylacetate:hexane) was further purified by preparative $\mathrm{TLC}$ using $\mathrm{CHCl}_{3}$ as solvent to yield the compound 2 which was pale yellow in color $(500 \mathrm{mg})$.Fraction D (4:1,ethylacetate:methanol) was purified to obtain compound 3 as pale yellow colour powder (50 mg). Ethanol fraction (4g) was column chromatographed over Sephadex LH 20 using various concentration of methanol and water as eluent at $100 \%$ methanol to afford compound 4as white crystalline solid $(10 \mathrm{mg})$. The detailed scheme is given in supplementary material (Figure S5).

4.5.Analytical Techniques. UV spectra were recorded on a Jasco V 550 UV-VIS spectrophotometer. IR spectra were recorded on a Perkin Elmer spectrum one Fourier Transform Infrared spectrometer with $\mathrm{KBr}$ pellets. ${ }^{1} \mathrm{H}$ and ${ }^{13} \mathrm{C}$ NMR spectra of compounds were recorded on a JEOL $400 \mathrm{MHz}$ NMR spectrometer in $\mathrm{CDCl}_{3}$ with TMS as internal standard and with chemical shifts $(\delta)$ reported in ppm. HRESIMS were measured on a Q-TOF micro mass spectrometer (Waters USA) in positive ion mode with methanol as solvent. Operating parameters of Varian E112 EPR spectroscopy instrumentwere as follows: Frequency: $9.23 \mathrm{~Hz}$, 
MicrowavePower: 10 mWMod. Constant: 3.2 G-Time Constant: 0.5Center Field: 3300 G-Scan range: 2000.All scans and sample positions were carried out with the same conditions.

4.6. Free Radical Scavenging Assay Using UV-Visible Spectroscopy. The antioxidant capacities of T.arjuna extracts were evaluated by measuring their free radical abilities to1,1diphenyl-2-picryl hydrazyl (DPPH) stable radicals following established procedureby measuring absorbance of $3 \mathrm{ml}$ of $100 \mathrm{mM}$ DPPH (ethanolic solution) that contained $20 \mu 1$ of extract (1 $\mathrm{mg} / \mathrm{ml}$ each extract). Ethanolic solution of $100 \mathrm{mM}$ DPPH was taken as the blank ${ }^{35}$. The disappearance of DPPH colour was measured spectrophotometrically at $517 \mathrm{~nm}$ (Jasco V 550 UV-VIS, Tokyo, Japan). Inhibition of free radical DPPH in percent (\%) byfollowing formula Inhibition $(\%)=100 \times\left(\underline{A_{b l a n k}}-\underline{A}_{\underline{s a m p l e}}\right) / A_{\text {blank }}$

where, $\mathrm{A}_{\text {blank }}$ is the absorbance ofDPPH solution without extract and $\mathrm{A}_{\text {sample }}$ is the absorbance of the tested extract.

\subsection{Free Radical Scavenging Assay Using EPR spectroscopy}

EPR spectroscopy was used to monitor the scavenging of DPPH radical by the TA extracts. $20 \mu 1$ of TA extracts were mixed with $100 \mu \mathrm{l}$ of methanolic solution of DPPH to a total volume of $3 \mathrm{ml}$ and the EPR spectrum was measured using VARIAN E-112 ESR spectrometer at different time points. $3 \mathrm{ml}$ of $100 \mathrm{mM} \mathrm{DPPH}$ in ethanol was taken as blank. The decrease in the intensity of DPPH peak, which was indicative of decrease in the concentration ofDPPH radical, was monitored by EPR spectrometer for a period of 30 minutes during which the radical was $\operatorname{stable}^{36}$.The DPPH radical was generated in ethanol solution and considered as a control (Figure S6). The DPPH radical scavenging activity was estimated as a ratio of individual DPPH signal peak height to that of control. 
DPPH radical scavenging activity

1- (A of Sample)/(A of Control)

The DPPH radical scavenging activity of each sample was calculated by comparison of relative peak height for control (sample free) DPPH solution. DPPH radical reducing activity of each test sample was expressed as the percentage of DPPH residue

4.8. Catalase Assay. Catalase decomposes hydrogen peroxide molecules into water and oxygen. The principle of the assay is that loss of the substrate measured at $238 \mathrm{~nm}$ until the substrate concentration becomes limiting. The assay was performed at $25^{\circ} \mathrm{C}$ using $50 \mathrm{mM}$ sodium phosphate buffer ofpH 7.0 containing $12 \mathrm{uMof} \mathrm{H}_{2} \mathrm{O}_{2}$ as substrate and $0.2 \mathrm{ugmL}^{-1}$ of bovine liver catalase. The absorbance was monitored at $238 \mathrm{~nm}$ as a function of time for $5 \mathrm{~min}$. One unit of catalase activity is defined as the amount of enzyme required to break one micromole of substrate per minute.Measuring the absorbance of reaction mixture at $238 \mathrm{~nm}$ for $5 \mathrm{~min}$ monitored the activity of catalase.When the reaction proceeds, absorbance at $238 \mathrm{~nm}$ starts decreasing due to reduction of substrateconcentration. The assay mixture contained $10 \mu \mathrm{g}$ of extracts, $63 \mu 1$ of $0.132 \mathrm{M}$ hydrogen peroxide, $70 \mu 1$ of $0.002 \mathrm{mg} / \mathrm{ml}$ catalase and the volume was made up to $700 \mu 1$ with $50 \mathrm{mMphosphate}$ buffer at $\mathrm{pH}$ 7.0. Assay with equal volume of corresponding solvent instead of extracts was used as blank. Similarly, Catalase assay was performed withcompound 4 from ethanol extract with increasing concentrations within the range of $10 \mu \mathrm{g}-50 \mu \mathrm{g}$ with the same conditions as described above. All the experiments were performed at least three times and the values mentioned are mean values within $\pm 5 \%$ standard error. 
4.9 Molecular Docking Studies. Molecular Docking studies were performed using UCSF Chimera and AutoDock Vina. The targets 3CL Pro (PDB-6lu7), PL-Pro and RNA-polymerase (PDB:6M71) were prepared for docking by adding hydrogen, assigning charges and removing water molecules using the dock prep module. The compound, which was to be docked, was minimized using AMBER forcefield and then docked using Autodock Vina. For 3CL-Pro, grid box of size $27 * 27 * 27$ centered at coordinates $(-16.1115,12.1099,66.6681)$ was made and docking was performed, That of PL-Pro grid box of size $29 * 29 * 29$ centered at coordinates ($1.84143,0.0274012,1.57883$ ) was made and docking was performed. For RNA polymerase the grid box of $35 * 29 * 30$ centered at coordinates $(-1.84143,0.0274012,1.57883)$. The pose with the lowest binding energy was considered as the best pose and saved for further study.

\section{AUTHORS}

Senthilkumar Arumugam-Applied and Industrial Microbiology Laboratory, Bhupat and Jyoti Mehta School of Biosciences, Indian Institute of Technology Madras, Chennai, 600036 India. Email:senthilorganic@gmail.com

Swati Sucharita Dash-Applied and Industrial Microbiology Laboratory, Bhupat and Jyoti Mehta School of Biosciences, Indian Institute of Technology Madras, Chennai, 600036 India. Email:swati.121@gmail.com

Kartik Mitra- Bioengineering and Drug Design Lab, Department of Biotechnology, Bhupat and Jyoti Mehta School of Biosciences, Indian Institute of Technology Madras, Chennai, 600036 India.

Email:kartik.mitra.v@gmail.com

Mukesh Doble-Bioengineering and Drug Design Lab, Department of Biotechnology, Bhupat and Jyoti Mehta School of Biosciences, Indian Institute of Technology Madras, Chennai, 600 036 India. (+91)-44-2257-4107, Fax: (+91)-44-2257-4102.

Email:mukeshd@iitm.ac.in

Sathyanarayana N. Gummadi-Applied and Industrial Microbiology Laboratory, Bhupat and Jyoti Mehta School of Biosciences, Indian Institute of Technology Madras, Chennai, 600036 India.

Email:gummadi@iitm.ac.in 


\section{CONTRIBUTION TO RESEARCH}

SNG contributed to supervision, experimental design, methodology, bioassay and manuscript editing.

SA contributed to structural elucidation, data analysis, bioassay andmanuscriptwriting.

SSDcontributed to data analysis and manuscript writing

MD and KM contributed to the docking studies.

All authors contributed to the review of the final the manuscript.

\section{CONFLICTS OF INTEREST}

The authors declare that they have no conflict of financial interest

\section{ACKNOWLEDGMENT}

The authors are deeply grateful for financial support provided by IDRP, Department of Biotechnology, IIT Madras. The authors gratefully acknowledge Dr. Sreevidya Narasimhan, CDRI, Lucknow. The authors wish to thank the SAIF, Department of Chemistry, IIT Madras for EPR, FT- IR, NMR, and ESIMS facility.

\section{REFERENCES}

1. WHO. The evolving threat of antimicrobial resistance: Options for action. Switzerland: WHO, 2012.

2. Dwivedi, S.; Chopra, D. Revisiting Terminalia arjuna -An ancient cardiovascular drug. $J$ Tradit. Complement. Med. 2014,4, 224-231.

3. Jain, S.; Yadav, P.P.; Gill, V.; Vasudeva, N.; Singla, N. Terminalia arjuna a sacred medicinal plant, phytochemical and pharmacological profile.Phytochem. Rev.2009, 8, 491502. 
4. Tripathi, V.K.; Singh, B. Terminalia arjuna- its present status (a review).Orient. J. Chem.1996, 12, 1-16.

5. Cooper, E.L. CAM, eCAM, Bioprospecting: the 21st century pyramid.Evid. Based. Compliment.Alternat. Med. 2005, 2,125-127.

6. Patil, U. H.; Gaikwad, D.K. Phytochemical evaluation and bactericidal potential of Terminalia arjunastem bark.Int. J. Pharm. Sci. Res.2011,2, 614-619.

7. Sumitra, M.; Manikandan, P.; Kumar, D.A.; Arutchelvan, N.; Balakrishna, K.; Manohar B. M.; Puvanakrishnan, M. Experimental myocardial necrosis in rats: role of arjunolic acid on platelet aggregation, coagulation and antioxidant status. Mol. Cell Biochem.2001, 224, 13542.

8. Dwivedi, S. Terminalia arjuna Wight \&Arn.-a useful drug for cardiovascular disorders. $J$. Ethnopharmacol.2007,114, 114-129.

9. Pawar, R.S.; Bhutani, K.K. Effect of oleanane triterpenoids from Terminalia arjuna-a cardioprotective drug on the process of respiratory oxyburst. Phytomedicine. 2005, 12, 391393.

10. Padma Sree, T. N.; Krishnakumar, S.; Senthilkumar, A.; Gopalakrishna, A.; Gummadi, S. N. In vitro Effect of Terminalia arjunabark extract on antioxidant enzyme catalase. J.Pharmacol.Toxicol.2007, 2, 698-708.

11. Manca,C.; Simon Paul, S.; Barry III, C.E.; Freedman, V.H.;Kaplan, G. Mycobacterium tuberculosiscatalase and peroxidase activitiesand resistance to oxidative killing in humanmonocytes in vitro. Infect. Immun.1999, 67, 74-79.

12. Day Jr,W. A.;Sajecki,J. L.; Pitts,T. M.;Joens, L.A. Role of catalase in Campylobacter jejuniintracellular survival. Infect. Immun.2000, 68, 6337-6345. 
13. Basu, M.;Czinn, S.J.; Blanchard, T.G. Absence of catalase reduces long-term survival of Helicobacter pylori in macrophage phagosomes.Helicobacter.2004,9, 211-216.

14. Newcomb, W.W.; Brown, J.C.Internal catalase protects Herpes Simplex virus from inactivation by hydrogen peroxide. J.Virol.2012,86, 11931-11934.

15. Roth, S.; Droge, W. Regulation ofT cell growth factor (TCGF) production by hydrogen peroxide. Cell. Immunol.1987,108, 417-424.

16. Schreck, R.; Rieber, P.; Baeuerle, P. A. Reactive oxygen intermediates as apparently widely used messengers in the activation of the NF-kappaB transcription factor and HIV- 1. EMBO J.1991, 10, 2247-2258.

17. Wu, F. A new coronavirus associated with human respiratory disease in China. Nature.2020, $579,265-269$.

18. Novel Coronavirus $\quad(2019-\mathrm{nCoV}) \quad$ situation $\quad$ reports -116 , 15May,2020https://www.who.int/emergencies/diseases/novelcoronavirus-2019/situationreports.

19. Hua, Y. C.; Chun, C. C. L.; Ta, C. L. Anti-herpes simplex virus type 2 activity of casurinin from the bark of Terminalia arjuna Linn.Antiviral Res.2002, 55, 447-455.

20. Justyna, P.; Moriola, B.S.; Ivana A. Study of the antioxidant properties of beers using electron paramagnetic resonance.Food Chem.2013, 141, 3042-3049.

21. Ningijian, L.; David, D.K. Antioxidant property of coffee components: Assessment of methods that define mechanisms of action.Molecules. 2014,19, 19181-19208.

22. Orhan, D.D.; Yeşilada, F.E.E.; Tsuchiya, K.; Takaishi, Y.; Kawazoe, K. Antioxidant activity of two flavonol glycosides from Cirsium hypoleucum DC through bioassay-guided fractionation. Turkish J. Pharm. Sci. 2007, 41,1-14. 
23. Zivkovic, J.; Zekovic, Z.; Music, I.; Tumbas, V.; Cvetkovic, D.; Spasojevic, I.Antioxidant properties of phenolics in Castanea sativa Mill.extracts.Food Technol.Biotechnol.2009, 47, $421-427$.

24. Sánchez, J.C.; Roberto Faure García, R.F.; Cors, M.T.M. 1,1-Diphenyl-2-picrylhydrazyl radical and superoxide anion scavenging activity of Rhizophora mangle (L.) bark. Pharmacognosy Res.2010,2, 279-284.

25. Ashby, E.C. Single-electron transfer, a major reaction pathway in organic chemistry. Answer to recent criticisms. Acc. Chem. Res.1988, 21, 414-421.

26. Mader, E.A.; Davidson, E.R.; Mayer, J. M. Large ground-state entropy changes for hydrogen atom transfer reactions of iron complexes. J. Am. Chem. Soc.2007, 129, 5153-5166.

27. Honda, T.;Miral, T.; Tsuyuki, T.; Takahashi, T.; Sawai, M. Chemical constituents from bark of Terminalia arjuna, Bull. Chem. Soc. Japan. 2001,49,3213-3225.

28. Sunyana, J.; Prem, P.Y.; Vikrant, G.; Neeru, V.; Neelam, S.Terminalia arjuna a sacred medicinal plant, phytochemical and pharmacological profile. Phyto.Chem. Rev. 2009, 8, 491-502.

29. Gauthaman, K.; Banerjee, S.K.; Dinda, A. K.; Ghosh, C.C.; Maulik, S.K.Teminalia arjuna (Roxb.) protects rabbit heart against ischemic-reperfusion injury: Role of antioxidant enzymes and heat shock protein. J. Ethanopharmacol. 2005,96, 403-409.

30. Karthikeyan, B.R.; Sarala Bai, K.; Gauthaman, K.; Sathish, K.S.; Niranjali D.S. Cardioprotective effect of the alcoholic extract of Terminalia arjuna bark in an in vivo model of myocardial ischemic reperfusion injury.Life Sciences. 2003, 73, 2727-2739.

31. Leff, J. A.; Parsons, P. E.; Day, C. E.;Oppegard, M. A.; Moore, E. E.; Moore, F.; Repine, J. E. Increased hydrogen peroxide scavenging and catalase activity in serum from septic 
patients who subsequently develop the adult respiratory distress syndrome. Am. Rev. Respir. Dis.1992,146,985-989.

32. Mani, J.S.; Johnson, J.B.; Steel, J.C.;Broszczak, D.A.;Neilsen, P.M.; Walsh, K.B.;Naiker, M. Natural product-derived phytochemicals as potential agents against coronaviruses: A review.Virus Res. 2020 Apr 30: 197989. doi: 10.1016/j.virusres.2020.197989

33. Stower, H. Lopinavir-titonavir in severe COVID-19. Nat.Med.2020, 26, 465.

34. Manli, W.; Ruiyuan Cao.; Leike Z.; Xinglou, Y.; Jia, L; Mingyue, X.; Zhengli, S.; Zhihong, H.; Wu, Z.; Gengfu, X. Remdesvier and chloroquine effectively inhibit the recently emerged novel coronovirus (2010-nCo-V) in vitro.Cell Res.2020, 30, 269-271.

35. Moure, A.; Franco, D. J.; Sineiro, H.; Dominguez, M.; Nunez, M.J.;Lema, L.M. Antioxidant activity of extracts from Gevuinaavellana and Rosa rubiginosa defatted seeds, Food Res. Int. 2001, 34,103-109.

36. Adevaiton, B. D. S.; Dulce, H. S. S.; Vanderlan, S. B.; Luciana, A. S.; Tome, M. S.; Oswaldo, B. Antioxidant properties of plant extract; an EPR and DFT comparative study of the reaction with DPPH, TEMPOL and spin trap DMPO. J. Braz. Chem. Soc. 2009, 20, 1483-1492. 


\section{Potential of Terminalia arjuna as a Promising PhytoremedyAgainst COVID-19: DPPH Scavenging, Catalase Inhibition and Molecular Docking Studies}

Department of Biotechnology, Bhupat and Jyoti Mehta School of Biosciences, Applied and Industrial Microbiology Laboratory, Indian Institute of Technology Madras, Chennai, 600036 India

*Corresponding author

Phone: (+91)-44-2257-4114, Fax: (+91)-44-2257-4102, Email: gummadi@iitm.ac.in

\section{Supplementary Information}




\begin{tabular}{|l|l|c|}
\hline S.No. & \multicolumn{1}{|c|}{ Contents } & Page No \\
\hline Figure S1 & $\begin{array}{l}|c| \\
\text { Reaction mechanism of 2,2-diphenyl -1-picrylhydrazyl (DPPH) }\end{array}$ & S3 \\
\hline Figure S2 & Structures of compounds isolated from T. arjuna bark extract. & S4 \\
\hline Figure S3 & ESI-MS spectrum of arjunetin isolated from ethanol extract & S5 \\
\hline Figure S4 & $\begin{array}{l}\text { ESI-MS mass spectral fragmentation analysis of arjunetin isolated } \\
\text { from T. arjuna bark ethanol extract }\end{array}$ & S6 \\
\hline Figure S5 & $\begin{array}{l}\text { Schematic representation of extraction of various fractions from } \\
\text { bark powder of T.arjuna. }\end{array}$ & S7 \\
\hline Figure S6 & EPR spectrum of DPPH radical in ethanol & S8 \\
\hline
\end{tabular}




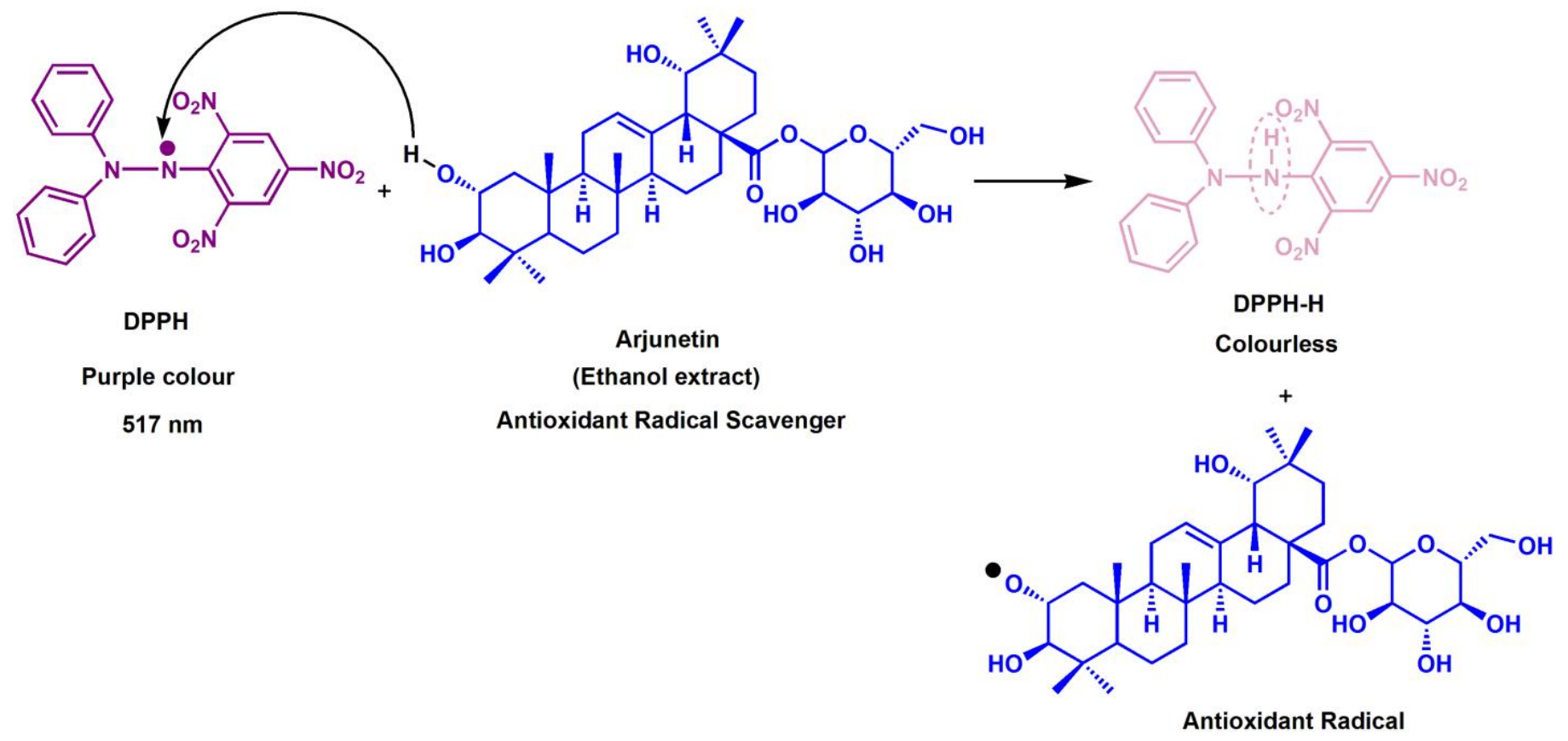

Figure S1: Reaction mechanism of 2,2-diphenyl -1-picrylhydrazyl (DPPH) with ethanol extract 


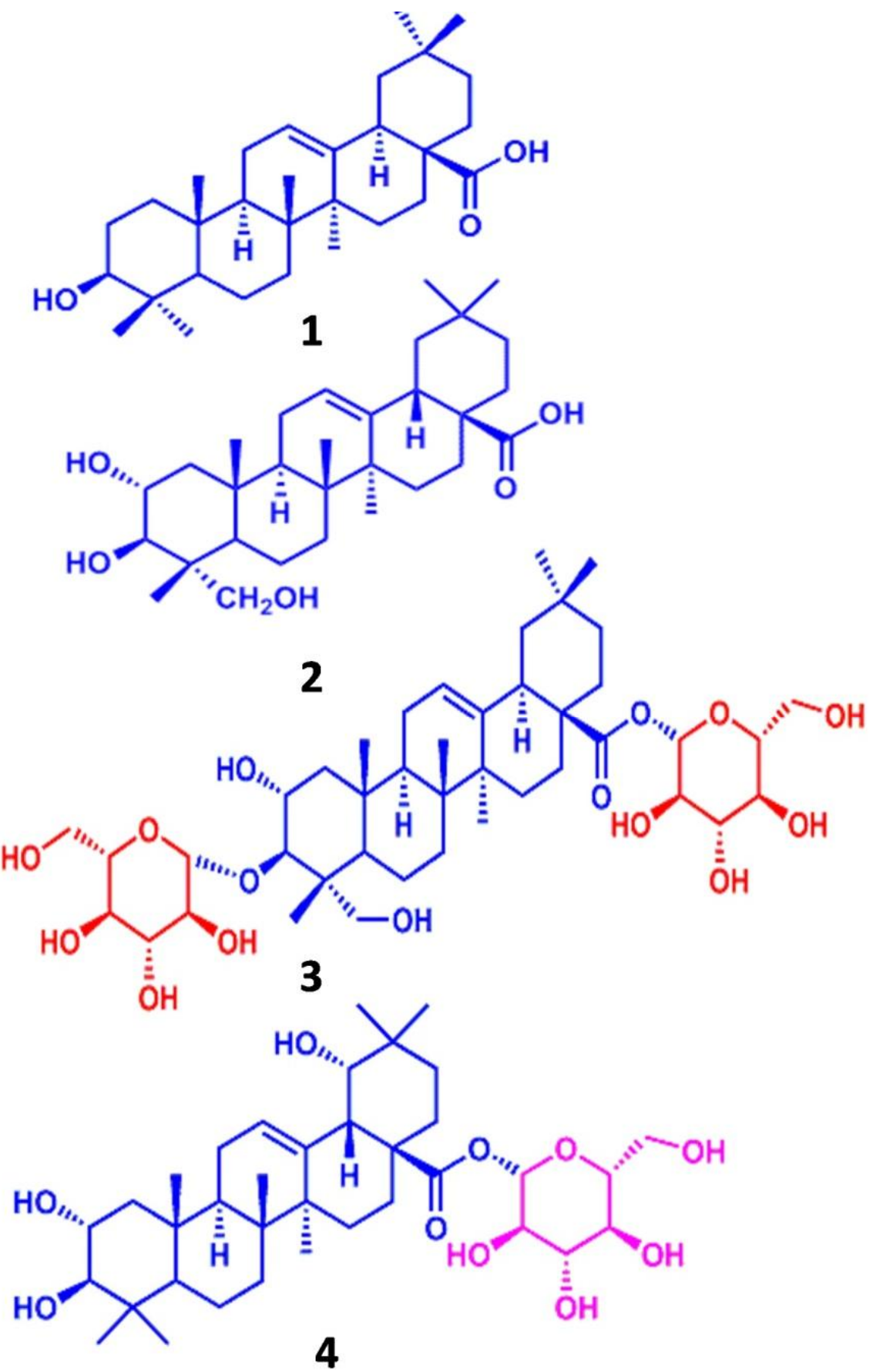

Figure S2: Structures of compounds isolated from $T$. arjuna bark extract.1. Oleanolic acid 2.Arjunolic acid 3.Arjunolitin 4.Arjunetin 


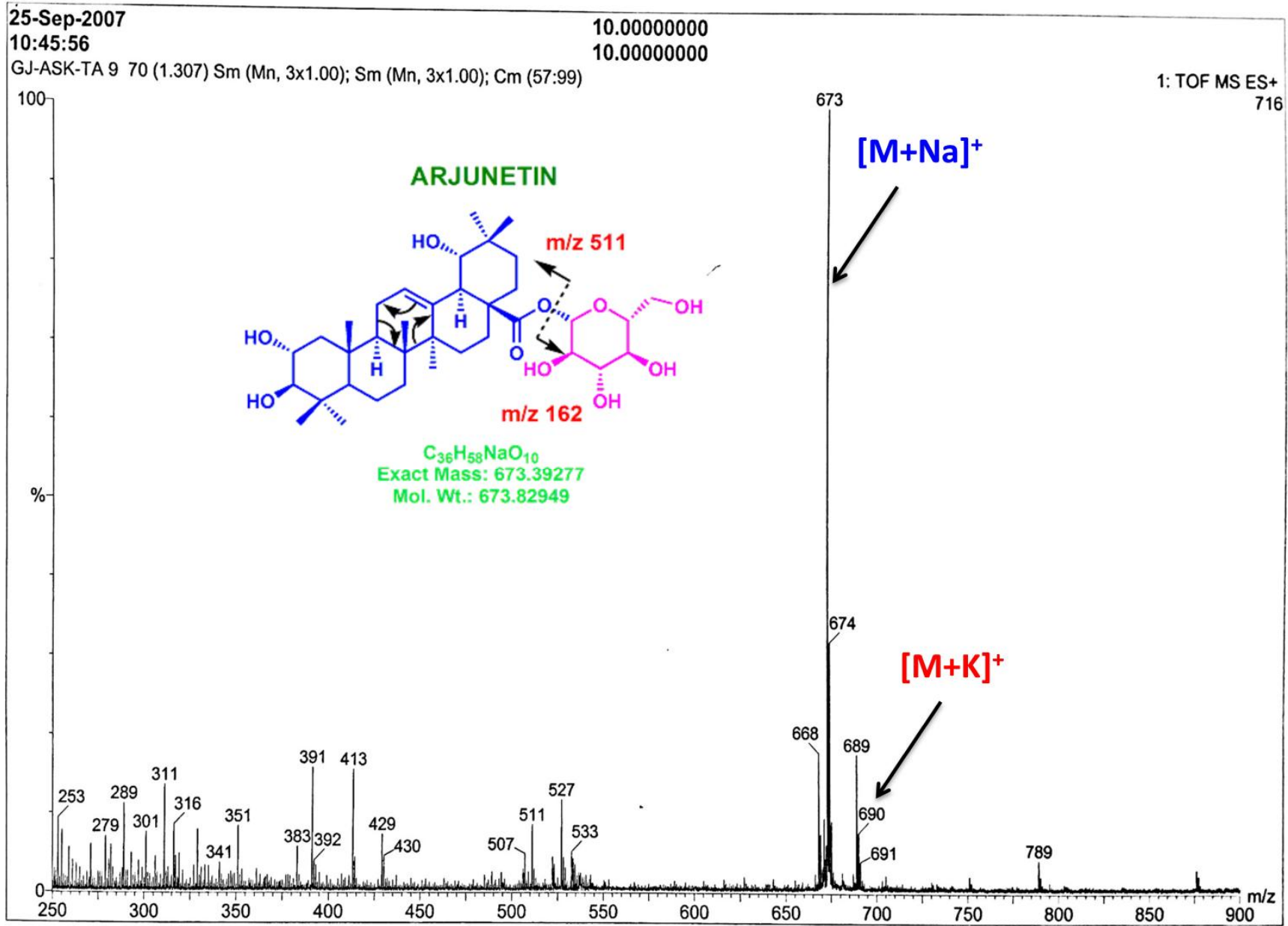

Figure S3: ESI-MS spectrum of arjunetin isolated from ethanol extract 


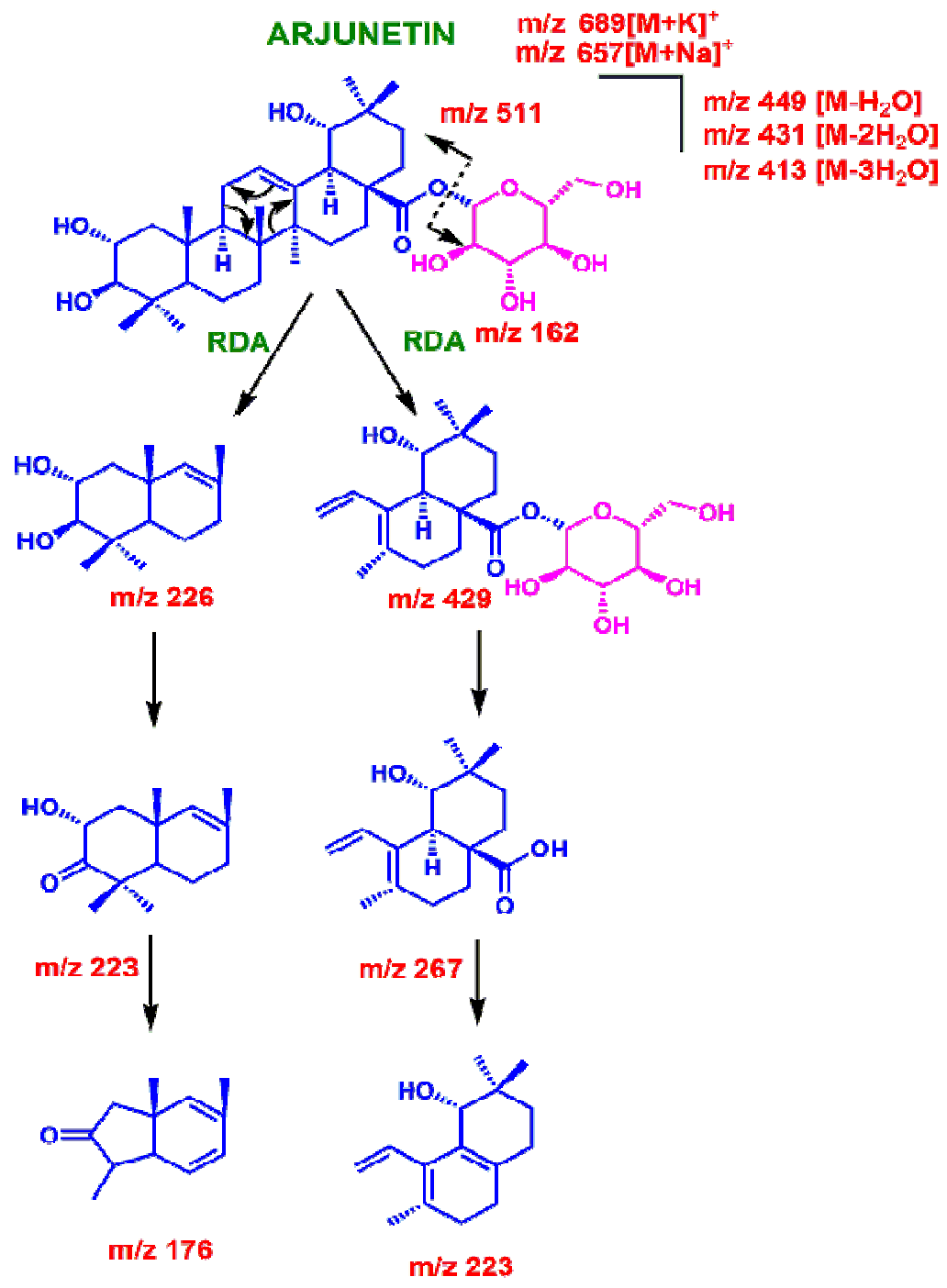

Figure S4: ESI-MS mass spectral fragmentation analysis of arjunetinisolated from $\boldsymbol{T}$. arjunabark ethanol extract 


\section{BARK POWDER $(1.5 \mathrm{Kg})$}

Extracted with hexane $5 \mathrm{~L}$ (Soxhlet apparatus)

72 hours

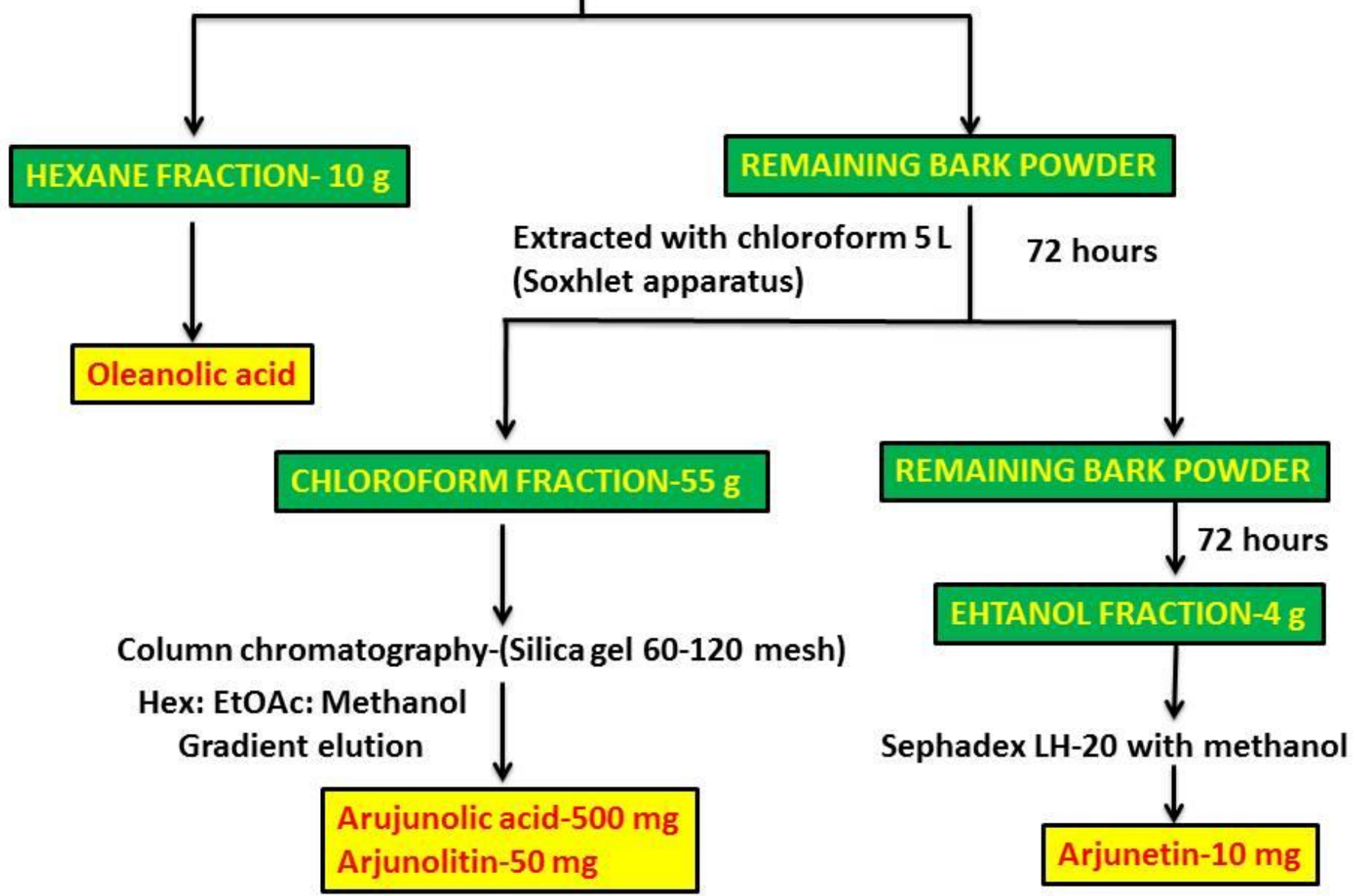

Figure S5: Schematic representation of extraction of various fractions from bark powder of T.arjuna. 


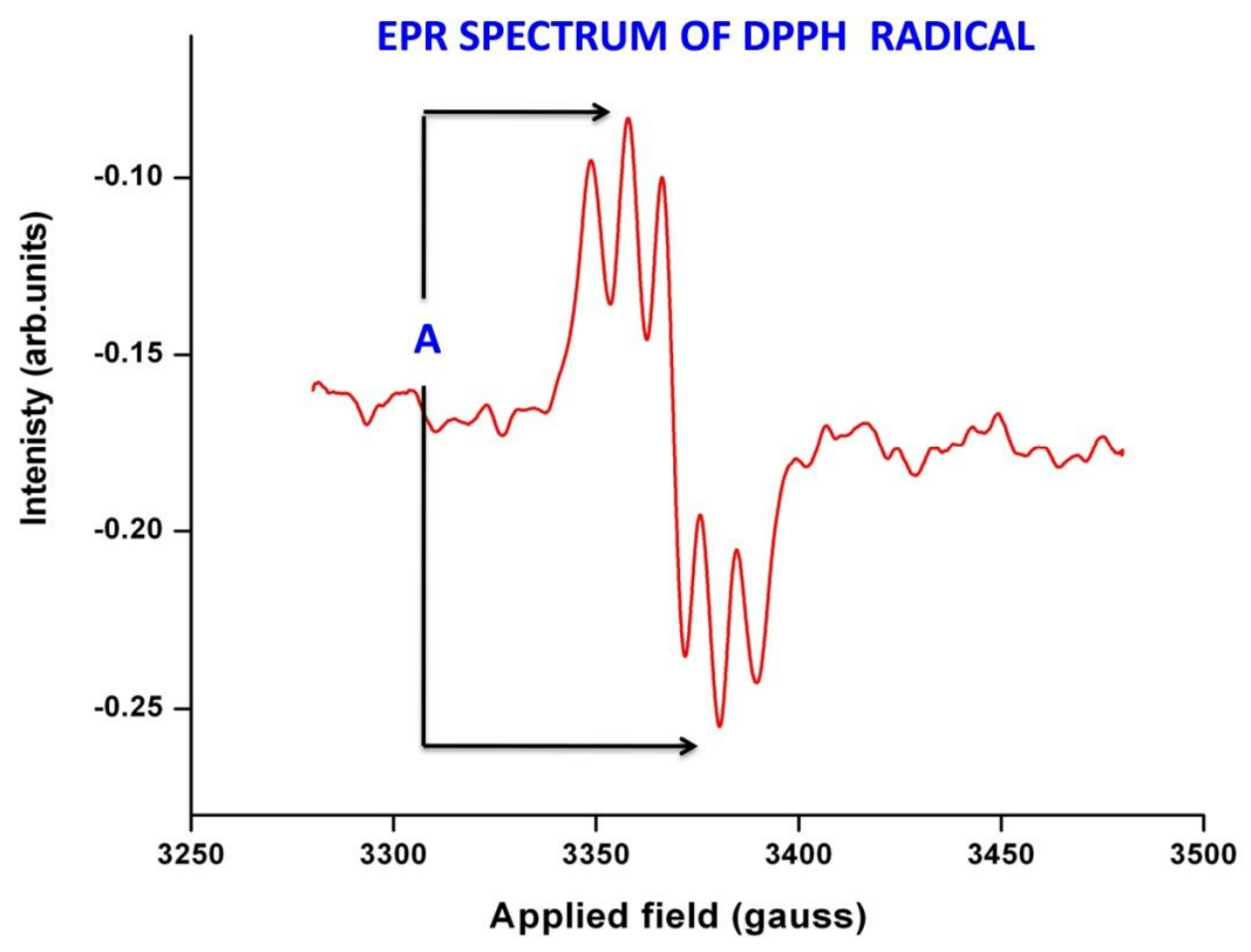

Figure S6: EPR spectrum of DPPH radical in ethanol 